\title{
LINGUISTIC KNOWLEDGE OF REALITY: A METAPHYSICAL IMPOSSIBILITY?
}

\author{
J. Nescolarde-Selva and J.L. Usó-Doménech \\ Department of Applied Mathematics. University of Alicante. Alicante. Spain. \\ M. J Sabán \\ Department of Philosophy. University Rey Don Juan Carlos. Madrid. Spain.
}

\begin{abstract}
Reality contains information (significant) that becomes significances in the mind of the observer. Language is the human instrument to understand reality. But is it possible to attain this reality? Is there an absolute reality, as certain philosophical schools tell us? The reality that we perceive, is it just a fragmented reality of which we are part? The work that the authors present is an attempt to address this question from an epistemological, linguistic and logical-mathematical point of view.
\end{abstract}

Keywords: Connotative significance, Denotative significance, Knowledge, Language, Mathematical things, Paradigm, Reality, Significant, Sintagm.

\section{INTRODUCTION}

Our starting point is the recognition of Reality that is beyond us, but we can get in touch in different ways. We have two great tools to access this reality:

1) Logic, to organize it and make it so manageable.

2) Language, to make it strong and to be able to share it.

Thanks to these tools (but not only them) build scientific theories and philosophical systems, discuss, argue, give lectures, write books, etc,... build new tools that we use to try to domesticate reality. The justification for this device is practical: we need to deal with Reality in order to operate on if, even though we know that what we are handling is made from a particular perspective. There is a radical difference between what we know and the continuous, complex and vast reality, that we dissect with some tools that simplify and reduce it to a manageable size.

There is an inadequacy of language and discursive thought to express reality, and, in general, there is a failure of systems to think about the world around us. Systematization, on the one hand is a natural tendency of the human spirit "to consider what we know as complete, and to make everything symmetrical" and, moreover, this is a trend that pays off many times, as systematization brings simplicity and therefore, ease of management and foresight. But we would be dogmatic if we thought that any useful tool can replace the real thing, or it can be applied with equal success to any reality. Put another way, the limitations of the two systems are:

1) Simplify systems, there is something of the Reality that the scheme does not catch.

2) Each individual situation is different, wanting to implement a known system instead of getting to the task of thinking is simply to refuse to look at the reality in front of us.

A particular case of this mismatch between our tools and Reality shows noting the conventional character limits classifications. In the areas of our expertise that is labeled as "matters of degree." We must recognize the vagueness of many of the concepts that 
result from a dissected reality. Since this is offered as continuous and gradual, our classifications artificially divide Reality and thus to be nuanced, it cannot be said nor thought of as absolutely clear whether a particular object is or is not within a a particular class. But recognizing the conventional nature of many classifications (and, therefore, the vagueness of their application) does not mean giving up our use of them. Yhis recognition leads us to know how to use the classifications without being totally committed to them. Classifications is a very useful tool: they are schemes to think, to describe, to teach and even to facilitate observation. But to know how to use a classification one needs to be aware of these instrumental difficulties. When this is understood, nothing prevents even that can serve different classifications for the same things: everyone can contribute something useful to the description of the reality that we know. And, even more, the next step is learning to think about reality in all its complexity is to know that all language can be seen as a great filing system, and that the right attitude is, again, the use of it without being overcome by it.

When we apply an attribute to a subject, what we are doing is to find a place within a simplified scheme in which the complexity of reality never quite fits. Consequently, to think it is necessary to distinguish reality of our expressions. And although this may seem banal advice, things are as they are, but when we try to explain how they are using language, the nature of this tool prevents us from working with a very finely tuned tool: we always get, whatever we try to do more or lesser generality, as a schematic representation, and therefore it has some unsuitability. Hence there is a danger of transferring the ontological plane to the linguistic level (moving from an attribute, for example, to a contradiction with reality that sometimes we think is useful). Again, thinking well requires recognizing the instrumental nature of Science, i.e., requires realizing that what Science gives us is not Reality and not the whole Reality. A recognition that, moreover, is not to deny the true nature of sciencetific knowledge. The sciences are systems that humans use to understand the world. Its schematic character provides distinct advantages over other types of knowledge (accuracy, reduction laws, predictability). But that same schematic character is the cause of a failure it is important not to forget.

One advantage of philosophical thought about the scientist is that, being less mediated by previous schemes, it is able to recognize the difference between reality and systematization. Philosophy acquires, in addition, a clarifying respect for science. In his effort to think more directly the reality, the philosopher realizes the systematization of all instrumental and is thus more able to place science, recognizing its value but also its limitations. Differences between knowledge are not essential, but of degree.

Human knowledge is the deployment of a unique way to open up to the world, but it moves to deepen successive levels of analysis. For example, a certain level of knowledge would be that of a scientist who studies the movement drawing on the notion of force, but it is possible to move to a deeper level, in which the scientist analyzes the notion of force, even making assumptions (without analyzing) about the data of perception, and it is possible, still, to move to a third deeper level where you begin to analyze the data before any categorization, thus passing to the philosophy of consciousness. Now, each new level represents a different level of generality and abstraction, on the one hand, and of clarity and precision, on the other. To deepen knowledge, one passes from the concrete to the abstract, from the general to the less general, and therefore from the diaphanous to the opaque. 
All these levels are deep knowledge, and not all knowledge may be grasped in the same way.

The highest degree of confidence in knowledge is attributed to the sciences: we have created tools with which we lock (or try to lock) accurate molds on reality, and therefore "is very easy to see and describe", i.e., it is easy to think about Reality linguistically and communicate it to others. Captured by a language with precise meanings, knowledge is solidified, like we can grasp with hands and lean on it. The systematization, rigid schemes of science are like a skeleton holding it up. But not just knowledge based on science: it is possible (and inevitable) to move to deeper levels. But as we go deeper, that is, as we think philosophically, we leave those precise tools and try to get in touch with reality more directly, or what is the same, roughly bounded by fixed patterns. Without the rigid systems skeleton, knowledge then becomes fluid: the words are no longer defined as a contour and therefore is more difficult to communicate and agree.

What is left is not so easily grasped, and this is the price paid for a plastic or flexible knowledge, which is better suited to the chiaroscuro of Reality. Delving deeper means abandoning a very precise knowledge of a small piece of Reality, and scrolling provides increasingly confused knowledge of ever wider areas of Reality.

At the level of science schematized reality is easy to describe, and the language puts everything in its place, but what we see is thus only a very poor picture of what we had before. In-depth analysis, widens the scope of known reality, but with some confusion: "more light more confusion", i.e., the more we soak in reality, the less it is systematized. And we realize, then, the artificial nature of those tools, that deep levels play no clear role. The best attitude with the tools is to take them for what they are and use what they are designed for.

Science gives us knowledge of reality that has the advantage of clarity and precision: with sharp tools it is much easier to handle reality(make understandable data, make predictions, discover new data...). But it would be absurd to believe that it is known to all, like trying for the same precision as philosophy of science. In contrast to the strength of science, the advantage is that where philosophy is concerned, in general, discourse about abstract realms of life pays the price of being content with less solid knowing.

\section{THE ACCESS TO REALITY}

Whatever the intended meaning of the famous saying of Protagoras, "Man is the measure of all things" it is ordinarily understood in an epistemological sense, as a statement of the relativity of all human knowledge, of the impossibility to penetrate beyond the appearance of things. And this interpretation is consistent with the general trend of the times in which Protagoras lived. The doctrine of Heraclitus on the perpetual flow and universal vision of Parmenides that plurality and change are just a reflection of reality, the vain attempts to explain the nature of sensory perception and explain the illusions and misjudgments, along with the beginnings of consciousness (evident in Democritus), a subjective factor in the process of perception, all this suggested to philosophers to distrust what their senses showed and rely exclusively on their reason or intelligence. With reflection, however, it soon became clear that rational theories could not claim boast of greater consistency than the experience of perception, and the inevitable result of this was that the relativism of Protagoras and his followers gradually became the skepticism of the Middle Academy. 
Modern relativism, on the other hand, although it tends to become skeptical, was originally a reaction against the latter. To dispell the doubt that Hume (1964) had suggested about the validity of universal synthetic judgments , Kant (1978) proposed that we should understand them as coming not from the apprehension of the real nature of things, but from the constitution of our minds. Kant argued that experience has a mental factor, hitherto neglected, that actually has a critical importance: it is responsible for space, time, categories and all forms of synthesis. It is the formal element that comes from the structure of the mind itself that organizes knowledge and makes it what it is. Hume was wrong to assume that knowledge is an attempt to copy reality. Not so. The world, as we know it, the world of experience, depends essentially on the human mind, from which derives unity, order and form. The obvious objection to such relativism is the thing-in-itself, which is not and can never be an object of knowledge. We were thus locked into a world of appearances, whose nature is constituted by our minds. We can never know what is Reality itself. Yet that is precisely what, according to Kant, we want to know. The fascination of Kant's philosophy lies in the fact that it gave full value to the activity, as opposed to the passivity or receptivity of the mind, but the unknowable Ding-an-sich was an abomination, a fatal inconsistency with its apparent power to solve the problem of human knowledge. It must be eliminated at all costs, and the easiest way to do this is to nip it in the bud, to abolish it, leaving us with a knowable Reality because Reality and knowledge are one thing, and in this task, the mind, human or absolute, plays a definitive role. The relativity of Reality, which took the place of the reality of knowledge, has been designed in various ways.

Occasionally, as in the case of Fichte and Hegel (1948), nature is opposed to the mind or spirit as two sides of the same thing: intelligence, or will, or even of the unconscious mind. At other times, Reality is conceived as an organic whole that somehow is manifested in finite centers of experience, seeking to reproduce in themselves Reality as it is. Unfortunately, they fail so that what they say, even being contradictory, must somehow asking to be accepted as true. They are as true as other truths in the sense that they aim to express Reality, but must be subject to an infinite reinterpretation before they become identical with that Reality to which they refer.

The modern absolutist, realizing the inadequacy of this position, has returned some independence to the physical order, which does not depend for its existence on my perception, but it depends on my perception with regard to the qualities and relationships we found in it. In other words, the "who" of the real world depends on our perceptual organs. Or that reality, before it is known, is merely raw material, while what we call a "thing" or object of knowledge, is raw materials processed by an appropriate mental process that gives it the attributes of spatiality and the like. Knowing, therefore, is to "induce the form of knowledge on the subject."

The relativity of Reality conceived this way, really means a return to Kant's position, except that instead of the thing-in-itself, with its character and unknowable properties, then is a kind of raw material, without qualities, attributes, or determinations, and consequently, as unknowable as the thing-in-itself, unknowable now because there is nothing to know. In this context, modern idealism paired with pragmatism and humanism, insists that Reality must be epistemologically seen as a raw material that is totally devoid of properties and totally indeterminate. The difference between the two views lies in that, for the idealist, the form is imposed on the subject by the very act by which we know it, while for the pragmatists, this does not happen until after a long philosophical experimental process. 
In his "Essais sur la connaissance" (Essay on knowledge) M. Fonsegrive (1909) discussed at length the issue of relativism, and in his opinion we must grant in a sense that knowledge is relative to our faculties. But, although he makes this concession universally, in fact his own theory is that only our knowledge of corporeal objects is what is considered strictly relative. We can know other minds as they are because we ourselves are thinking beings, and the internal manifestation of our mentality and that of others are of a similar nature. But "we know the essence of things, and the essence of our relationship with things. Among the laws of nature themselves, us know less than we do of our dealings with nature." "What we know, is known as the subject." The main argument on which this relativism rests is basically the same as used by Berkeley in his famous "Dialogue between Hylas and Filonous" (Stoneham, T., 2002). Hence, what we know is never the subject as it is in itself, but only in terms of our knowledge of it. Obviously, the above argument is valid if the notions of "being in itself" and "being known as" are mutually exclusive, but this is not the way it is conceived by the realist or anti-relativist. Being in-itself merely means being as it exists, although it is not known. This means that the nature and existence of being is prior to our knowledge of it (a fact that Fonsegrive holds firmly), and does not mean that being, as it exists, can not be known. The Fonsegrive argument (1909) proves nothing against the opinion which states that the real nature of the object is knowable if the thing, in the abstract, is not the thing that exists that is known, in concrete, there is no reason not to actually say that what is existing in nature can be known, or, in other words, that it can not be known as it is.

The argument that relativists to try to prove the relativity of Reality is precisely similar to the above: We can not think about real things, except insofar as they are objects of experience, from which it follows that their reality depends on your relationship with mind. This argument is patently false. All that it proves is that things should be, or else become objects of experience in order to be known by the mind. But no proof that things must, by their very nature, be objects of experience. Unless Reality is intelligible and can fall within experience, it can not become an object of thought. In no other way can the possibility of knowing the thing assume its "connection to the mind." Definitely to know something is to bring it into the field of consciousness, but it just continues to be conceivable that, things should be able to become objects of consciousness.

Psychological considerations compel us to admit that Reality, when experienced, transformed, or better, is reproduced as a psychic fact, but we cannot conclude that reality itself, the reality that is the object of experience and which refers to our experience as something external to itself, necessarily a psychic fact. Experience or perception obviously are conditions without which we cannot think anything about things, much less think about them as existing, but that in no way means that experience and perception are conditions that things may exist. When we think, we do not ordinarily think of things as objects of experience, but simply as "things", real or imagined. And when we name the properties of the things, we think of them as belonging to things and not superinduced by our minds. However, our natural way of thinking could be wrong. Even granting that what "appears" is the Reality, appearances can be false. They may be fully or partially due to our minds and, consequently, did not reveal the nature of Reality, but rather their relationship with us-as-learners, and with our faculties and our organs.

Most of the arguments presented in support of this theory are based on psychology, and while psychology makes responsible judgments, the arguments are far from conclusive. We are invited to believe that abstraction and generalization are subjective processes 
involved in every act of knowledge, essentially modifying its contents. But abstraction is not a forgery, unless we assume that we are considering the abstract as if it exists in the concrete, that is, that there is not a connection with, and mutual dependence of other things, that are isolated and independent, as we understood it.

Nor is generalization false, unless we assume, without proof, that there really are individuals to whom our concept potentially applies. In a word, neither these nor any other of the subjective processes and ways of thinking destroys the validity of knowledge if we distinguish, as we should, that which is purely formal and subjective, of what belongs to the objective content and what refers to the actual order of causes and purposes.

Another argument is derived from the alleged relativity of sensation, from which all knowledge is derived in the scholastic theory of knowledge. It is said that the quality of sensation is largely determined by the character of our nervous system and, in particular, by the receptors of our different senses.

1) First, it is at least probable, however, that the quality of sensation is determined by the stimulus, and in any case, the objection is unnecessary because the argument does not refer us to our sense of objects as such, but as qualities that ignore nature, although we know that our senses may differ in varying degrees. Even if we should grant that the feeling is on our specialized organs of sense, we can not conclude in any way that the knowledge gained by the sense involves a subjective determination.

2) Second, the sense data give us not only qualitative differences, but also spatial forms and magnitudes, distance, motion, speed, direction, and these data with quantitative data as in mathematics and physical science.

3) Third, sensory data, that are partly sûbjective, have an objective cause as a condition. Consequently, a theory that explains sense data, successfully assigned conditions that are no less real than the purposes to which they give rise, at least partially.

4) Finally, if knowledge is really relative in the sense explained above, although it may satisfy our practical efforts, it can never satisfy the speculative. The goal of the speculative research is knowing Reality as it is. But knowledge, if it was only for appearances, would have no real meaning, and would be conceived as a kind of a priori idealism, neither would it have a purpose.

Kantian commonly taught that relationship is the category of categories. Matter and motion "consist of relationships." In fact, reality as we know it is nothing more than a set of relationships because "the nature of the mind is such that no knowledge can be acquired or expressed, and consequently no real existence can be conceived if not to through a system of relations" (Renouvier, 1891).

This form of relativism can be called objective, to distinguish it from the relativism we have discussed above, and which, in fact, it is usually combined. This is, first, a theory of the nature of knowledge, but also a metaphysical knowledge to identify with Reality. Such a view is a theory of the nature of the relationship and is very different from that of the Scholastics. For the latter, the relationship requires:

1) A subject to which it belongs.

2) Something special in the subject to explain what it proclaims.

3) A term, other than itself, to which it relates. 
A relationship, in other words, according to modern thinking, presupposes its "terms". There is a mysterious and invisible link that somehow unites two aspects of one thing and makes them one. A relationship can be mutual, but if so, there are actually two relationships (e.g., Paternity and filiation) belonging to different subjects, or, if the same, arises from different principles. It is true that in science, as in other things, we learn a relationship without being able to discover the nature of the relationship linking entities. We know, for example, the pressure and temperature vary proportionately in a given mass of gas whose volume is kept constant, not knowing with certainty the final nature of the pressure and temperature. But we do know something about them. We know they exist, that each of them has a peculiar nature, and it is because of this nature that there is this relationship between them. We cannot know a relationship without knowing some of the things it relates, since the relationship presupposes its "terms". Therefore, the universe cannot consist of relationships, but it must be composed of interrelated things.

\section{REALITY AND FORMAL LANGUAGES}

Referring to formal languages, mathematicians seem reluctant to refer to the " concepts existing behind the symbols" as meaningless, or to claim that mathematical entities are non-existent, and this reluctance is sufficiently justified because of the pejorative nature of such terminology. The ontological status of mathematical entities, as matter of paradox, has a long history of philosophical debates,perhaps because of their close relationship to the problem of universals.

\subsection{The Spinozian thought}

As with Hobbes and Descartes, Spinoza is impressed with mathematics as a kind of knowledge - because of the certainty of its proofs and demonstrations. More than any other thinker we have seen, however, Spinoza carries to the furthest extreme the peculiarly modern effort to establisha complete philosophy in which mathematics is not simply a part (as with Plato): rather, this philosophy is one that is entirely subsumed under the mathematical model. This means that Spinoza's assumptions at the outset preclude what we have seen to be a considerable problem in the modern period especially with Hobbes and Descartes. That is, especially with Descartes, who recognizes a considerable split between the world of sense-knowledge and the mathematical dimensions of mind, the problem we are left facing is one of explaining or justifying the relation between pure mathematics and the sensory world. Spinoza simply assumes that reality is co-extensive with the world of mathematical entities and relations. That is, there simply is no other reality than reality as mathematically described: anything which presents itself as "reality" - but which is not mathematically "capturable" - is simply illusion.

\subsection{Mathematical platonism}

For Platonism entails that reality extends far beyond the physical world and includes objects which aren't part of the causal and spatiotemporal order studied by the physical sciences. Mathematical Platonism has considerable philosophical significance. If it were true, it would put great pressure on the physicalist idea that reality is exhausted by the physical. Mathematical platonism, if true, would also put great pressure on many naturalistic theories of knowledge. For there is little doubt that we possess mathematical knowledge. Mathematical Platonism would therefore establish that we have knowledge 
of abstract (and thus causally inefficacious) objects. This would be an important discovery, which many naturalistic theories of knowledge would struggle to accommodate. Although these philosophical consequences are not unique to mathematical Platonism, this particular form of Platonism is unusually well suited to support such consequences. For mathematics is a remarkably successful discipline, both in its own right and as a tool for other sciences. So if philosophical analysis reveals mathematics to have some strange and surprising consequences, it would be unattractive simply to reject mathematics. A form of Platonism based on a discipline whose scientific credentials are less impressive than those of mathematics would not be in this fortunate situation. Working realism is the methodological view that mathematics should be practiced as ifPplatonism was true (Bernays 1935, Shapiro 1997). This requires some explanation. In debates about the foundations of mathematics Platonism has often been used to defend certain mathematical methods, such as the following:

1) Classical first-order (or stronger) languages whose singular terms and quantifiers appear to be referring to and ranging over mathematical objects.

2) Classical rather than intuitionistic logic.

3) Non-constructive methods (such as non-constructive existence proofs) and nonconstructive axioms (such as the Axiom of Choice).

4) Impredicative definitions.

5) Hilbertian optimism, that is, the belief that every mathematical problem is in principle solvable.

According to working realism, these and other classical methods are acceptable and available in all mathematical reasoning. We assume that mathematical Platonism is true. Then clearly the language of mathematics ought to be as described in (1). Secondly, provided it is legitimate to reason classically about any independently existing part of reality, (2) would also follow. Thirdly, since Platonism ensures that mathematics is discovered rather than invented, there would be no need for mathematicians to restrict themselves to constructive methods and axioms, which establishes (3). Fourth, there is a powerful and influential argument due to Gödel that impredicative definitions are legitimate whenever the objects being defined exist independently of our definitions. If this is correct, then (4) would follow. Finally, if mathematics is about some independently existing reality, then every mathematical problem has a unique and determinate answer, which provides at least some motivation for Hilbertian optimism.

By the standards of philosophy, Abstractness has remained relatively uncontroversial. Among the few philosophers to have challenged it are Maddy (1990) (concerning impure sets (Nescolarde-Selva et al. 2012 ${ }^{\mathrm{a}, \mathrm{b}}$; Nescolarde-Selva and Usó-Doménech, 2013 ; Nescolarde-Selva and Usó-Doménech, 2013; Usó-Doménech and NescolardeSelva, 2013) and Bigelow (1988) (concerning sets and various kinds of numbers). It is a plausible prima facie constraint on any philosophical interpretation of mathematical practice that it should avoid ascribing to mathematics any features which would render actual mathematical practice misguided or inadequate. This constraint makes it hard to deny that the objects of pure mathematics are abstract. For if these objects had spatiotemporal locations, then actual mathematical practice would be misguided and inadequate, since pure mathematicians ought then to take an interest in the locations of their objects, just as physicists take an interest in the locations of theirs. The fact that pure mathematicians take no interest in this question suggests that their objects are abstract.

\subsection{The Gödelian thought}


Gödel strongly stated his own position (Gödel, K, 1934, 1964ª,b):

1) Classes and concepts may, however, also be conceived as real objects, namely:

a) Classes as "pluralities of things" or as structures which consist of a plurality of things.

b) Concepts as the properties and relations of things that exist independently of our definitions and constructions.

2) It seems that the assumption of such objects really is as legitimate as the assumption of physical bodies and there is enough reason to believe in their existence. There is the same sense necessary to obtain a satisfactory system of mathematics as well as physical bodies are necessary for a satisfactory theory of our sense perceptions and in both cases it is impossible to interpret the propositions.

These paragraphs should be tested extensively and formulated carefully because they contain subtle but crucial distinctions. It must be admitted that there is an important difference between Gödel's statement that "Classes and concepts may, however, also be conceived as real objects" and "classes and objects are real objects." If it were a question of just how classes and concepts have been designed, then the fact of employing "thing" in the language of mathematics could beconsidered as an extension of our everyday expected discourse, then one would have a fit, and a heuristically valuable exposure method, that is perhaps devoid of ontological presupposition. Even if one grants that we have "something of a perception" of mathematical objects, it is difficult to imagine what would be a phenomenological exposition of mathematics, or if it is at all possible. Thus the choice of language does not seem justifiable in epistemological priority areas, whereas Gödel âpparently discovered that in the case of sensory perceptions, sense data are epistemologically prior to physical objects, the latter being a necessary theoretical assumption.

Gödel makes a strong comparison between "the question of the objective existence of the objects of mathematical intuition" and the "question of the objective existence of the external world" which he considers to be "an exact replica". We are inclined to believe that this comparison does not respond to the fact that mathematics is not universally understood in the same way that the physical world which is "accessible" to virtually everyone. Applying "mathematical intuition" in this way tends to establish that the mathematician is a "visionary", which is not precisely Gödel's intention , because we like to believe that "mathematical truths" are as accessible as the "physical truths" i.e., common physical objects. However, if what Gödel says is that "physical intuition" is the intuition of physical things, the comparison is more accurate, since physical entities are perhaps as equally "abstract" as those of mathematics. Arguments involving "our knowledge of the external world" are mostly at the level of "furniture".

Similar difficulties exist in the problem of mathematical objects and the problem of physical objects. In both cases, our everyday discourse is a "language of the thing." Although the question of our perception of physical objects has centered around the discussion of sensory data, it is difficult to build a similar entity for mathematics.Gödel, in his analysis of Russell's comparisons between "axioms of mathematical logic and the laws of nature and logical evidence to sensory perception" said arithmetic is "elemental and indisputable evidence that compares more appropriately to sensory perception. " However this does not answer the question of how we "perceive" arithmetical truths. 
For the manipulation of symbols, this reduces in some way to the perception of physical objects, i.e., the symbols themselves.

The "logical evidence" or "math data" can be seen as a test of numerical computations, and reasoning from tables and diagrams and as follows:

1) The theorems of number theory are often generalizations of the "observation" of the calculations. Statements about prime numbers and multiple numbers can be considered as generalizations (laws) obtained from the convention that 7 is a prime, and 6 is a multiple, etc. Euclid's Theorem, claiming the infinity of prime numbers, can be "verified" by the calculation as indicated above. The axioms of arithmetic allow us to demonstrate this assertion in general, to make it possible for these sensory perceptions to be deduced. For any given prime number, we have always been able to obtain one more.

2) Tables and diagrams are shown to be the heuristically valuable in algebra and geometry. Historically, geometry is the science of measuring physical objects. Tables can be used to list the elements of a group and the results of a particular composition to "verify" the theorems of group theory, such as "counting" the number of its subgroups. Such tables are an algebraic aspect of the "experiments with physical objects."

3) The issue of computability is down to the ability to perform specific operations on the theoretical calculating machines, i.e., the task of representation "physical objects": algorithms are frequently called calculations. This name originates from calculi (small pieces of limestone) that the Romans used for the calculations.

4) Many problems to do with "large cardinality" stem from the observation that certain infinite cardinal family have particular properties, and the question is about the existence of other (usually non-enumerable).

5) Those propositions which, if true, are extremely strong axioms of infinity.... Contradicting Mahlo axioms, the truth (or consistency) of these axioms are an immediate consequence of the basic intuitions underlying abstract theory of sets. However, the new axioms are based on fairly strong arguments from analogy, such as the fact implied by the existence of Stone's representation theorem of Boolean algebras concerning operations with many elements.

If it is credible to "perceive" or "experience" calculations examining mathematical objects and constructions, then one is in a position to offer an interpretation of Gödel's idea of 'real'. Gödel stated "I believe that mathematical objects exist independently of our building and our having an intuition of them individually...". If mathematical objects were finite in number, "an intuition of them individually could be" possible. But this is not even possible for integers. For example, there is a finite and effective procedure by which we can test to see if an integer is prime. Although it is possible in principle to test any given integer (not taking into account the amount of time and material required due to the current state of technology), it is impossible to test all integers. When you accept Euclid's theorem, you must accept the existence of a prime number according to Euclid's Theorem, not because it has been proven ${ }^{1}$.

\footnotetext{
${ }^{1}$ Euclid offered the following proof published in his work Elements (Book IX, Proposition 20) and paraphrased here. Take any finite list of prime numbers $p_{1}, p_{2}, \ldots, p_{n}$. It will be shown that at least one additional prime number exists that is not in this list. Let $P$ be the product of all the prime numbers in the list: $P=p_{1} p_{2} \ldots p_{n}$. Let $q=P+1$. Then, $q$ is either prime or not:
} 
So we must recognize the existence of mathematical objects that we are unable to examine (experience), even if the domain is restricted to infinite potential objects. Then the "phenomenalist" mathematician, who supports mathematical truths to the extent that they are verifiable, to examine calculations and constructions, shall be required to place a limit on the size of finite structures depending on the technological ability to scrutinize such objects. However, it may be objected that the "phenomenalists" mathematicians could accept these truths, which are theoretically "testable" by evidence, and cannot reject the potentially infinite need. Then they appear as "theoretically verifiable", which would inevitably reduce some form of "normative behavior" of mathematical objects, and the problem reappears in a different form.

Let us realize that Gödel distinguishes the existence of different knowable objects: discussing the third form of Vicious Circle Principle, he indicated that mathematical objects can be assumed to exist independently of our constructions, and the third form of the principle is not violated if the means are presumed to assume existence and not cognition. This tends to corroborate our identification of "experiential knowledge" with "examining constructions and calculations." Although "phenomenalism"(mathematical extends to allow potential infinity, and allows classical analysis, because it is unreasonable to maintain that a whole is uncountable and "in principle subject to question."

Taking the classical analysis as a criterion for "a satisfactory mathematical system", we are forced to acknowledge the existence of mathematicalobjects, which we have no way, even from the beginning, to examine. Thus, "mathematical objects exist independently of experience, as opposed to being phenomenal or apparent, and are therefore real. That is, we replace "regardless of our building and our having an intuition of his individuality" to "independently of experience."

With the real interpretation given above, Reality is nothing more than a system of real objects. For a system of real objects, we mean that the objects of mathematics are governed by regularities. Axioms are mathematical objects as physical laws are to physical objects. One argument in favor of this view is the fact that no mythological allusion is in any of the writings of Gödel. Gödel seems to be saying that mathematical objects are so specific, so stable, and so well educated as physical objects, and that the axioms actually govern their behavior. In this respect, mathematical objects are neither illusory nor ephemeral, not any invention or any allegory. They are real. It can be seen, however, that one aspect of Gödel use of existence, its relationship to the criterion of intimate clarity, allows a comparison to their use by other philosophers, Descartes and

a) If $q$ is prime then there is at least one more prime than is listed.

b) If $q$ is not prime then some prime factor $p$ divides $q$. If this factor $p$ were on our list, then it would divide $P$ (since $P$ is the product of every number on the list); but as we know, $p$ divides into $P+1=q$. If $p$ divides into $P$ and $q$ then $p$ would have to divide into the difference of the two numbers, which is $(P+1)-P$ or just 1 . But no prime number divides 1 so there would be a contradiction, and therefore it cannot be on the list. This means at least one more prime number exists beyond those in the list. This proves that for every finite list of prime numbers, there is a prime number not on the list. Therefore, there must be infinitely many prime numbers. It is often erroneously reported that Euclid proved this result by contradiction, beginning with the assumption that the set initially considered contains all prime numbers, or that it contains precisely the $n$ smallest primes, rather than any arbitrary finite set of primes. Although the proof as a whole is not by contradiction, in that it does not begin by assuming that only a finite number of primes exist, there is a proof by contradiction within it: that is the proof that none of the initially considered primes can divide into the number identified above. 
Hume in particular. Gödel stated that he "only requires general math concepts should possess sufficiently clear value for us to recognize their authenticity and the truth of the axioms about them ....". Here we find a subtle but important distinction between intuition and clarity. We have an intuition that what can be said is clear. The concepts, for example of infinite totalities may be clear, however, our intuition of these entities may be quite weak. For example our intuition of elementary arithmetic and logic allows us to formalize such theories with strong enough convictions and general acceptance. Our intuition of large numbers in cardinal arithmetic, and the logic exists about them is much weaker. No one can say that these arguments are immediate. However, most mathematicians would agree that these concepts are unclear, although it is something basic or primitive. For us to be able to distinguish two different powers of infinity, is evidence for the belief that the Dower concept of infinite is clear.

Descartes (1960) discusses the concept of a triangle in a manner remarkably similar to the position held by Gödel that mathematical entities are not mind-dependent. Descartes's commentary on the case of a triangle "maybe there can be no figure outside my thought anywhere in the world " raises a problem in that some critis seem to misunderstand Gödel. Gödel is indicating that there is an analogy between the existence of mathematical objects and the existence of physical objects. He never claimed them to be physical objects, or that they existed in space and certainly not in any "mythical"sky. How can they be then? Perhaps in the sense of David Hume(1964):

'Twill not be surprizing after this, if I deliver a maxim, which is condemn'd by several metaphysicians, and is esteem's contrary to the most certain principles of human reason. This maxim is that an object may exist, and yet be no where: and I assert, that this is not only possible, but that the greatest part of beings do and must exist after this manner.

The computability or physical interpretations are of secondary importance. It depends if it is understood in the sense of actual real physical existence (in space and time), and then mathematical objects are not real. Subsequently factual reality and mathematical reality are often considered synonymous, and if so it can be a source of confusion.

Another aspect of existence in mathematical contexts that should not be confused with "the existence in terms of clarity", is existence in the sense of consistency. Mathematicians often wonder if there are certain objects for which properties are specified. In the context of the discussion, it is clear that the question being asked is whether the assumption of the existence of such objects is consistent with other axioms that have been alleged, and unfortunately, they are not always specified.

One might ask whether Gödel believed that mathematical truths are "eternal" since he thought that mathematical objects exist "independently" of the experience. Can one not see the inconsistency between his idea of mathematical existence and the idea that mathematical truths are eternal. We can resist any effort to read "mythology" in their thinking about the existence of mathematical objects. Gödel's realism, then, can be seen as a form of scientific realism without mythological or ontological commitments. So your ideas agree with Carnap $(1942,1964,1967)$, and are a fact that indicating his belonging to the Vienna Circle.

Ontological questions arise in considering mathematical objects as real objects, "believing in its existence" represents an area of contention among many philosophers who, for the most part, agree on the methods and content of mathematics. These critics 
do not dispute the clarity or the need for a proper development of language, as it was understood by Gödel, but can not agree with the ontological status of mathematical objects. Arguably the viewpoint that the content and mathematics methods are crucial, however, ontology is secondary or should be ignored completely. Therefore, it is considered that these disagreements do not make any changes to the content or mathematical methods, because they are seen as linguistic or verbal disputes, arguments over words and not things.

Gödel's realism, while similar to that of Locke and Leibniz, "forces us to consider axioms as true." This answers a question, nor touched by neither Locke nor Leibniz, why choose a system or a set of axioms, and not another with the implication that the choice of a mathematical system is not arbitrary.

\subsection{Benacerraf's thought}

Although Benacerraf (1965) focuses on arithmetic, the objection naturally generalizes to most pure mathematical objects. Benacerraf opens by defending what is now known as a structuralist view of natural numbers, according to which natural numbers have no properties other than those they have in virtue of being positions in an $\omega$-sequence. For instance, there is nothing more to being the number 3 than having certain intrastructurally defined relational properties, such as succeeding 2, being half of 6 , and being prime. No matter how hard we study arithmetic and set theory, we will never know whether 3 is identical with the fourth von Neumann ordinal, or with the corresponding Zermelo ordinal, or perhaps, as Frege suggested, with the class of all three-membered classes (in some system that allows such classes to exist) ${ }^{2}$. Benacerraf now draws the following conclusion: Therefore, numbers are not objects at all, because in giving the properties ... of numbers you merely characterize an abstract structureand the distinction lies in the fact that the "elements" of the structure have no properties other than those relating them to other "elements" of the same structure. (Benacerraf 1965)

In other words, Benacerraf claims that there can be no objects which have nothing but structural properties. All objects must have some non-structural properties as well. Both of the steps of Benacerraf's argument are controversial. The first step-that natural numbers have only structural properties - has recently been defended by a variety of mathematical structuralists. But this step is denied by logicists and neo-logicists, who claim that the natural numbers are intrinsically tied to the cardinalities of the collections that theynumber. And the second step-that there can be no objects with only structural properties - is explicitly rejected by all of the structuralists who defend the first step.

\section{REALITY AND NATURAL LENGUAGES}

There are different kinds of objects, which are characterized by different mental acts by which objects are perceived in their environment (Meinong, 1904). The objects of perception are different from those of thought but the latter are no less "objective" than the previous ones: they are "apprehended" by thought, but do not consist of it. Meanings and judgments are examples of this second type of object: in Meinong's terminology, they "hold together" (bestehen), while individual beings and qualities "exist". In this sense, the objects of thought can be real without existing in the technical

\footnotetext{
${ }^{2}$ What the number 3 means depends on the definition of a number.
} 
sense given by Meinong, and mathematical objects are of this kind. An intellectual inquiry is not linked to the empirical existence of objects, no existential presupposition is needed for their objects to be and be made "real" in an exactly specific sense. The object as such is indifferent to the nature of existence.

Analysis is needed of how speaking a language can be used in a given domain of objects. The first condition is (Agazzi, 1992) that these objects are there, and this is done through an act of speech, and through the presence of these objects in the subject's thinking. Phenomenological truth, the phenomenological situation such that an object just by being there, gives the subject an irrefutable and perhaps the only irrefutable witness of itself. This presence is the phenomenological situation covering this term through all possible ways to be present, and to suspend any judgment about the ontological status of what is present. Phenomenological truth has the following characteristics:

1) It is unstable, because it enables the subject to remain within the Kingdom of the Truth when he leaves the immediate presence of being.

2) It is private, because of the presence of certain objects only to the individual and these objects are really and instantly present.

It is possible to say (Agazzi, 1992) that the fundamental function of language is to overcome these limitations, enabling the subject to "preserve" the truth somehow beyond the moment of its immediacy and making it intersubjective. Thus, the characteristic of truth that is intrinsic to the phenomenological situation is transferred to language, as demonstrated by the fact that the commonuse of the term "true" referring to propositions of a language. And when is attributed primarily it denotes a state of the objects which are present phenomenologically. But the language itself can enter the field of presence, and this, in two respects:

a) It is present with its structures and forms.

b) It is "denotant", that is, regarding the presence of another sector.

The referential position is the position of the phenomenological presence of the object. And the absolute truth of a sentence is the coincidence with the situation of the phenomenological presence. Language should have tools able to retain the presence of objects even if they are really there. And these tools are the meanings that appear to be drawn from the referential situation, but not coincident with it, although they may even stay out of this sifuation. Meanings or are only partially understandings and "faithful" with respect to any particular phenomenological presence or what a referential situation might indicate. The concept "man" does not contain all the details of every single man could be denoted through it, but it is not doing that to denote men who do not share all the details.

Concepts are mental entities and, as such, are private. For collective evolution should be associated with the expressions of a language. This step determines the formal level, defined here as the fulfillment of conditions for explanation without ambiguity, so that the correct application of these conditions should enable men to understand other "meanings" using certain expressions. This phase entails the creation of a complex structure, since the small size of the present phenomenological analyzes, not only through a complex network of mutually interwoven meanings, but the language itself must somehow reproduce the complexity of this meaning -structure so that it can make a statement. This is the reason why language or semantics or the ability to convey meaning, necessarily presupposes the possession of a certain syntactic structure. On the 
other hand we have a syntactic structure, with different components which can be seen as having the ability to convey meaning (Carnap, 1942, 1964, 1967; Chomsky, 1963, $1965,1969)$ in a way analogous to the meanings that are able to denote referents. The significant propositions also denote phenomenological presence and say they are true, and an important part of the syntax is the exploration of the domain structure of "true statements".

The Tractatus Logico-Philosophicus (Wittgenstein, 2001) embodies an individualistic, universalistic and atomistic of knowledge and the world. Anything that can be thought can be said, so that the limits of language are the limits of thought (Giddens, 1976). Wittgenstein set out to build the unique language of a universal science, an attempt based on the relation of isomorphism between words in a sentence and the world objects it designates, that is, on a label or nominal theory of language that really has dominated Western civilization since Plato. This theory holds that words are tags or labels attached to objects in the world. Wittgenstein's second theory is based on a theory of language as well, somehow, a theory encoded in society (Gellner, 1998): Humanity lives in cultural communities, attached to forms of self-legitimized life that can only be described, not justified or explained, because in themselves they constitute the endpoint of any validation. When trying to find transcultural or extracultural reasons to the customs, the type of error emerges that has generated all philosophy. Wittgenstein denies the possibility of finding outside linguistic practice what these cultural forms govern, and introduces, the concept of language game (Wittenstein, $1988^{\mathrm{a}}$ ). Wittgenstein assumes that naming objects in the world (nominal or referentialfunction of language) is just one of many things that can be done with language. We name things and we can refer to them in speech, as if the act of naming already were given when we speak. Language games are nothing other than different uses of language depending on the context in which it is used, so there are as many language games as various uses of it. They refer to the fact that "speaking the language" is part of an activity or a form of life (Wittgenstein, $1988^{\mathrm{b}}$ ), whereby when language games change concepts change and, with them, the connnotative significances of lexemes. In this context, "following a rule" does not mean merely to know and apply it mechanically, because understanding the rule is essential for its proper application in the appropriate contexts, as well as in new situations (Ulin, 1990). Winch $(1964,1990)$ considered that if reality is constituted through language games, it may be concluded that our sense of reality is the result of a social construction of intersubjective character from conventional discourse in a languagecommunity. The notions of reality and rationality are relative to the conceptual framework of a community. It is not reality that gives meaning to the language. The real and the unreal are displayed in what language has. Both the distinction between real and unreal as well as the concept of correspondence with reality belong to our language. According to this hypothesis, unrelated linguistic communities, may have incommensurable or mutually intelligible worldviews, and may be therefore incomparable. Asking if reality is intelligible involves questioning the relationship between thought and reality. Considering the nature of thought leads us to consider the nature of language. Thus the question of the intelligibility of reality is inextricably linked to this other question: how to connect language to reality, what does it mean to say something (Winch, 1990). Rationality is thus not simply the informal logic of life a linguistic community shares within a specific cultural tradition.

But a language (formal or otherwise) on the one hand says "more" and on the other "less" about what is true of intentional or related models (Agazzi, 1992). This means that no language can fully and properly express phenomenological presence. The 
linguistic description of the subject is cheating with respect to what is present inhis thought. Moreover, a party receiving a Subject's linguistic communication will interpret to denote a presence for him, an added additional failure. This is equivalent to saying that absolute truth is not intersubjective. Another limitation is that it can cover the whole domain of true propositions that are expressible in language.

Semantic Incompleteness Principle (J. Nescolarde-Selva, 2010; J.L. Usó-Domènech and J. Nescolarde-Selva, 2012; J. Nescolarde-Selva and J.L. Usó-Domènech, 2013 ${ }^{\text {b }}$ : It is not possible to totally characterize a structure of objects or processes, through a language (formal or not), or to totally even dominate a portion of "truth" that this language can express about these objects or processes through its deductive operation.

\section{Consequences:}

1) There is an inadequacy of the semantic dimension relative to the benchmark or phenomenological situation.

2) There is a mismatch of the dimension in relation to the reference syntactical semantics.

Language is relative as well. How can we speak about absolute being, then? We can and we cannot. But that we cannot completely speak about $\mathrm{Git}$, it is not a reason to stop speaking about it (Wittgenstein, 1953), because we can incompletely represent its completeness We would not be able to speak about anything, because languages are incomplete. Language is used inside a context. Depending of this context, the language will be different. The Semantic Incompleteness, Principle is a consequence of Gödel's famous theorem (1931) and NWET (Non Wished Effects` Theorem; J. Nescolarde-Selva, 2010; J.L. Usó-Domènech and J. Nescolarde-Selva, 2012).

Beings do not have an intrinsic meaning and they only transform themselves into signs when we invest them with meaning. The signs are significant units that take form from words, images, sounds, gestures and objects, studied within a system of semiotic signs, like means or code.

Definition 1: The sign is the unit able to transmit representative contents, that is to say, it is a being that is named a significant, that is perceived by the senses, and that in the communicative process carryies information for the Subject.

In any process, we can distinguish between having a significant like an inherent property, and having a significance like it is related to the rest of processes of the Reality, that the Subject considers as a system. (Usó-Domènech, J.L., J. Mateu. 2004; Nescolarde-Selva, J.A., 2010; Usó-Doménech, J.L and Nescolarde-Selva, 2012; Nescolarde-Selva and Usó-Doménech, 2013 ${ }^{\mathrm{a} \cdot \mathrm{b}}$ )

Definition 2: The existence of information is independent of the existence of a Subject able to decode the message. This objective information is termed significant $\mathrm{S}$.

Definition 3: The information in a message acquires meaning if a Subject decodes the message. This subjective information is termed significance $\mathrm{s}$. 
Let $\mathrm{B}$ be a Belief system and $\mathrm{L}$ be a language both forming a doxical filter ${ }^{3}$.

Definition 4: Each significance $s$ is function of the components of a doxical filter, that is to say, the Belief system $B$ and its associated language $L$, so that $s=f(B, L)$. This function $f$ we will call the significance function.

Therefore, significant $\mathrm{S}$ is an ontic property, considering that the significance s will be part of a system of meaning. A significant is absolute and infinite, significance is relative and finite. The significant comes from absolute being and significance generates the relative being. The significant is interpreted as the material or physical form of the sign and is something that can be caught (perception) by some of the traditional senses of the human being. The significance, on the other hand is a mental construction. In our approach, the significant has a veritative value equal to 1 , that is to say, $v(S)=1$, whereas the significance has as veritative value a real number positive $v(s)$, between 0 and 1 , where 0 corresponds to absolute ignorance of significant (therefore of the process) and 1 to absolute understanding, that is to say,. $\mathrm{V}(\mathrm{S})=\mathrm{v}(\mathrm{s})$

The subject receives two types of semiotic stimuli:

a) Significant of his process or being.

b) The significant of the transmitted semiotic stimulus or significant of the significance.

This fact forces us to distinguish two types of significant:

Definition 5: The A-significant (A-S) or significant of first order, is the significant that is inherent to beings, processes or phenomena of the referring context.

Definition 6: The B-significant (B-S), significant of second order or connotation, is the significant of significance s.

Connotation B-S has a veritative value v'(B-S) = 1 having simultaneously, a relative veritative value or connotative veritative value $v(s) \in[0,1]$. That is to say, we received solar light rays with significant $\mathrm{S}$ and a significance s of the light, Sun, etc, concepts with a veritative value $v(s) \in[0,1]$, having relative significant $(\mathrm{B}-\mathrm{S})$ with a veritative value v'(B-S) $=1$.

Consequence 1: The significant $\mathrm{S}$ or significance s depends entirely on the level in which it operates in the analysis. Then, that which is significance in one level of the context; it can be significant in another one.

\footnotetext{
${ }^{3}$ The significant coming from the sign becomes significance after passing through a filter or sieve, which we will call the doxical filter. This filter consists of two essential components: the language and the belief system.
} 
Definition 7: Denotation (d-s) is the literal, obvious definition or the common sense of the significance of a sign.

Definition 8: Connotation (c-s) are socio-cultural and individual associations, the ideologies derived from the belief systems, belonging to the psychology of the Subject, and that is the indirect function of the Semiotic Environment (context) in which it is immersed.

Both distinctions involve the use of learned codes. The significance $s$ tends to be multiplied from an individual sign, until it is equipped with many meanings that go beyond that which the sign says now. Different orders from meaning or levels of significance exist:

1) The first order of significance is exactly the one of the denotation (d-s), in whichlevel exists a sign consisting of significant $\mathrm{S}$ and significance s.

2) The connotation (c-s) is a significance of second order that uses the denotative sign (with significant and significance) as significant, with an additional associate significance.

This distinction considers the connotation (c-s) as a sign that is derived from the significant of a denotative sign, so that the denotation takes us to a chain of connotations. Denotation (d-s) is an underlying and primary significance.

Consequence 2: Changes in the form of the significant $\mathrm{S}$ can generate different connotations (c-s).

Consequence 3: The definition of the connotation (c-s) of a sign is the set of possible senses or significances, depending on contexts and Subjects.

Consequence 4: The denotation (d-s) is most stable and apparently verifiable of the connotations.

Consequence 5: If the sign is something that interposes, interpreted by the Subject, we can affirm that the sign always has a connotation (c-s), and a denotation ( $d$-s) that is only the dominant connotation, to be interpreted as the true meaning of a being, process or text.

Consequence 6: The relative veritative value of denotation (d-s) or denotative veritative value will be $v^{\prime}(d-s)=1$.

We are going to call $s$ the systemic significance that is a denotative significance. We will call $\zeta$ the set of significant (signs) of Reality and $\zeta_{\Sigma}$ the set of systemic significants, that is to say, the parts of signs that have been limited by the Subject when establishing the borders of the system, and so that $\zeta_{\Sigma} \subset \zeta$.

Definition 9: $A$ denotative systemic significance (d-s) $s_{\Sigma}$ is a function defined in $\xi$ so that if $\xi_{\Sigma} \subset \xi$ then $s_{\Sigma}\left(\xi_{\Sigma}\right) \subseteq \xi_{\Sigma}$

Note 1: A denotative systemic significance (d-significance) is the significance of the absolute beings. 
Note 2: Denotative systemic significance (d-significance) refers to relative beings.

In agreement with Saussure (1984), signs are organized in codes in two ways: paradigms and syntagms. These two dimensions are represented like axes of a bidimensional space, where the vertical axis corresponds to paradigm and the horizontal axis represents syntagm (Nescolarde-Selva and Usó-Doménech, 2013 ${ }^{\text {b }}$ (Fig 1).

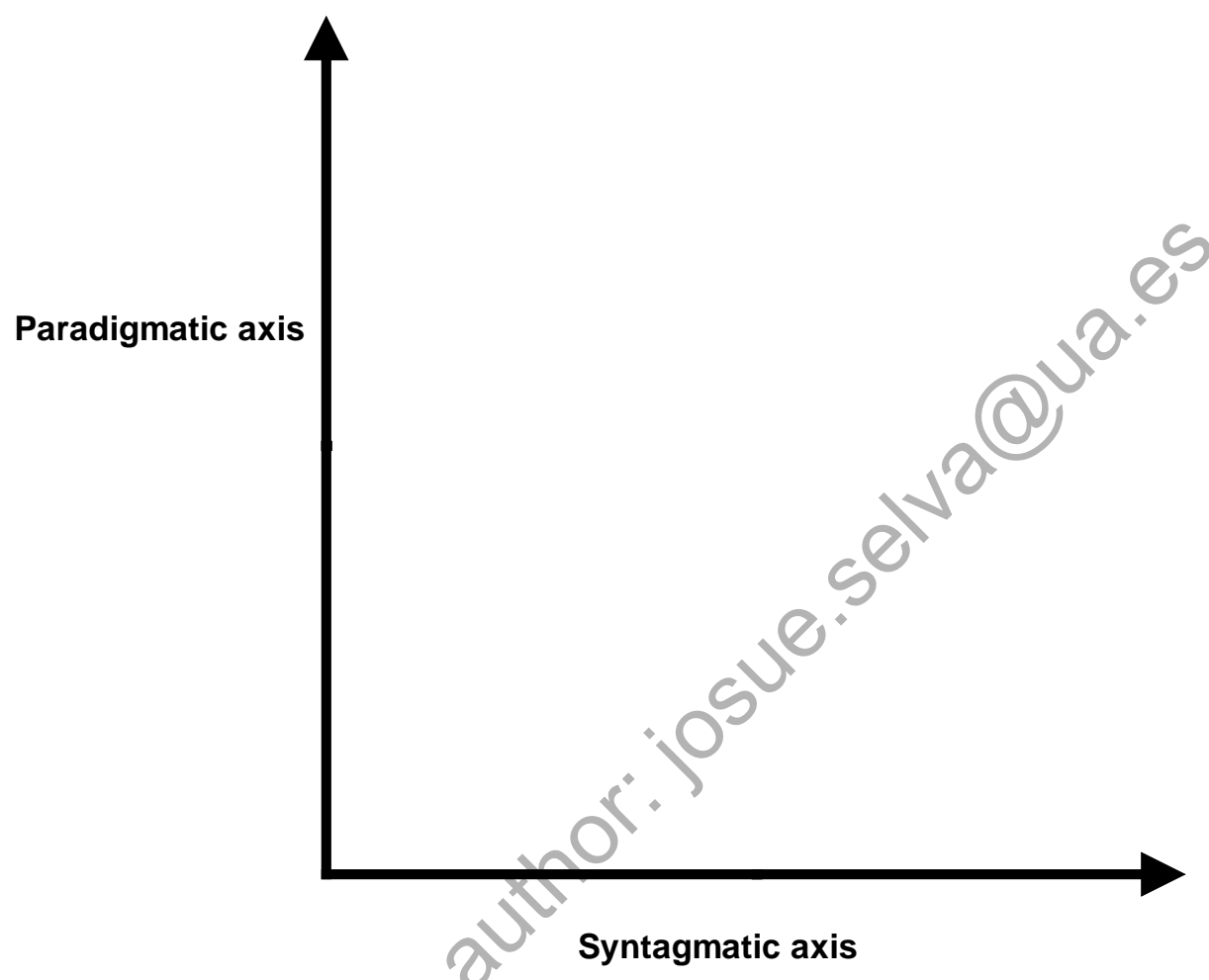

Figure 1: Saussure's bidimensional space.

In a three-dimensional space, the plane of the paradigm is the one of choice whereas the plane of syntagm corresponds to combination.

Definition 10: The syntagm is a combination of ordered significances, which interact, forming a totality with sense, in a form of chain of elements often ordered in a linear form.

These combinations are constructed within a set of rules and syntactic conventions. Syntagmatic relations are the varied forms in which the elements of one system can be related. Significance is sintagmatically related as a synchronous form to other significant ones at the same level and constituting their context. Syntagms are defined as sequential and therefore temporary. They can also represent space relations. (Figure 2). 


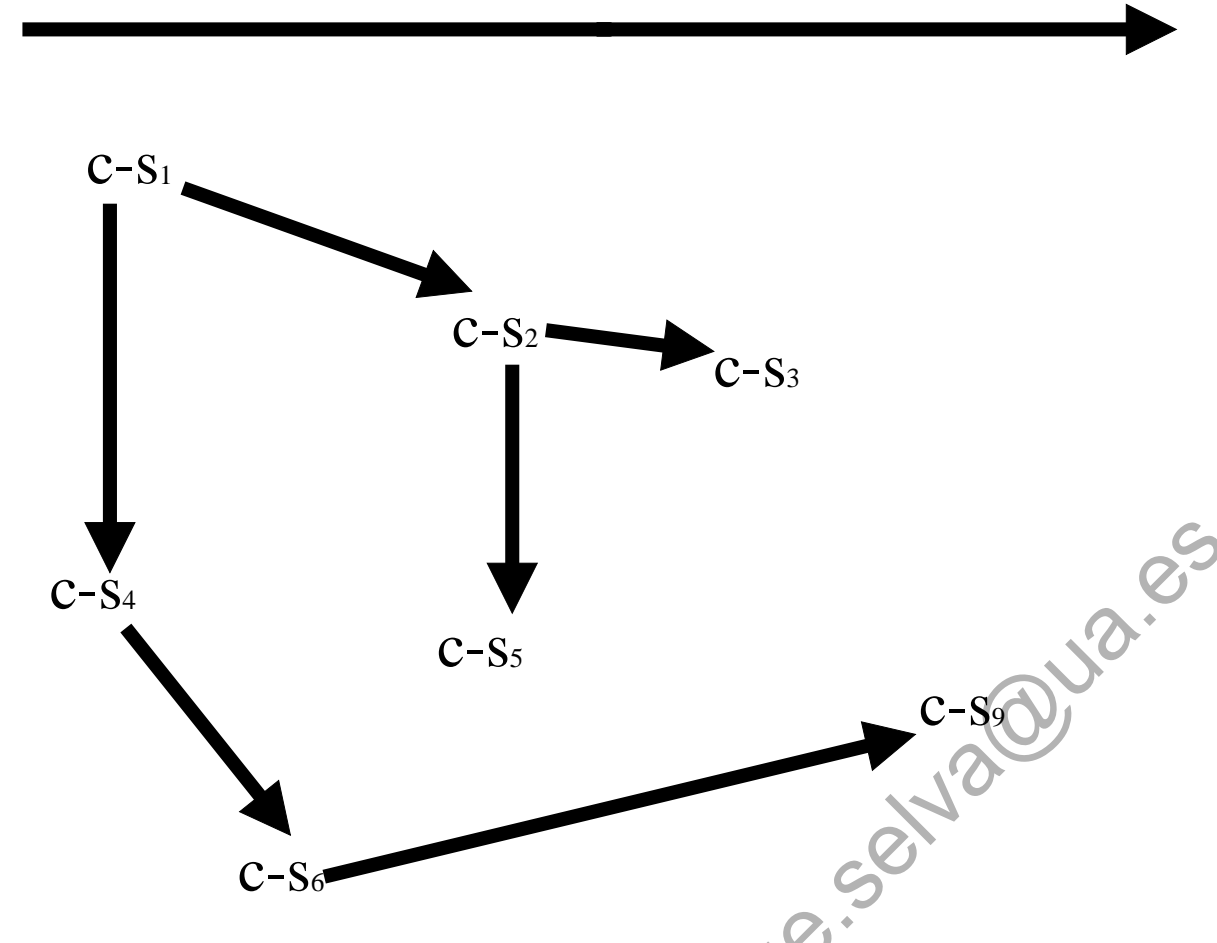

Figure 2: Chain of connotative significances.

Consequence 7: Syntagms are created according to the concatenation of significances in paradigmatic sets, chosen according to their property, conventional or required, by means of a determined system of rules, like grammar.

Consequence 8: In syntagms, the significance of a syntagmatic unit comes determined by means of its relation with other syntagmatic units. Syntagms tend to narrow these same significances according to the context.

Consequence 9: In a paradigm, the significance comes determined by the way it is different from other significances, in the sense that the paradigms conceive a possible world plurality.

Consequence 10: Paradigms expand the Reality, whereas syntagms contracts it.

For Hjelmslev (1968), the study of the comprehension-connotation goes outside of linguistic studies: the connotations appear as a content having as a plan of expression the set extension-designation of language. The connotations correspond to the upper levels of language. The study focuses within the semiotic frame, or a general study of signs (not just linguistic signs).

Let $c-s_{i}$ and $c-s_{j}$ be two connotations. In the common practice of the language, proximities have been verified on the syntagmatic axis. 
Let $\boldsymbol{\rho}_{\mathbf{i}}$ be a connotative chain and $c-s_{j}^{i}$ be connotative significances. The code will be of the following way (Figure 3):

$\begin{array}{llll}\rho_{1} & \rho_{2} & \rho_{3} & \rho_{n}\end{array}$

PARADIGMATIC

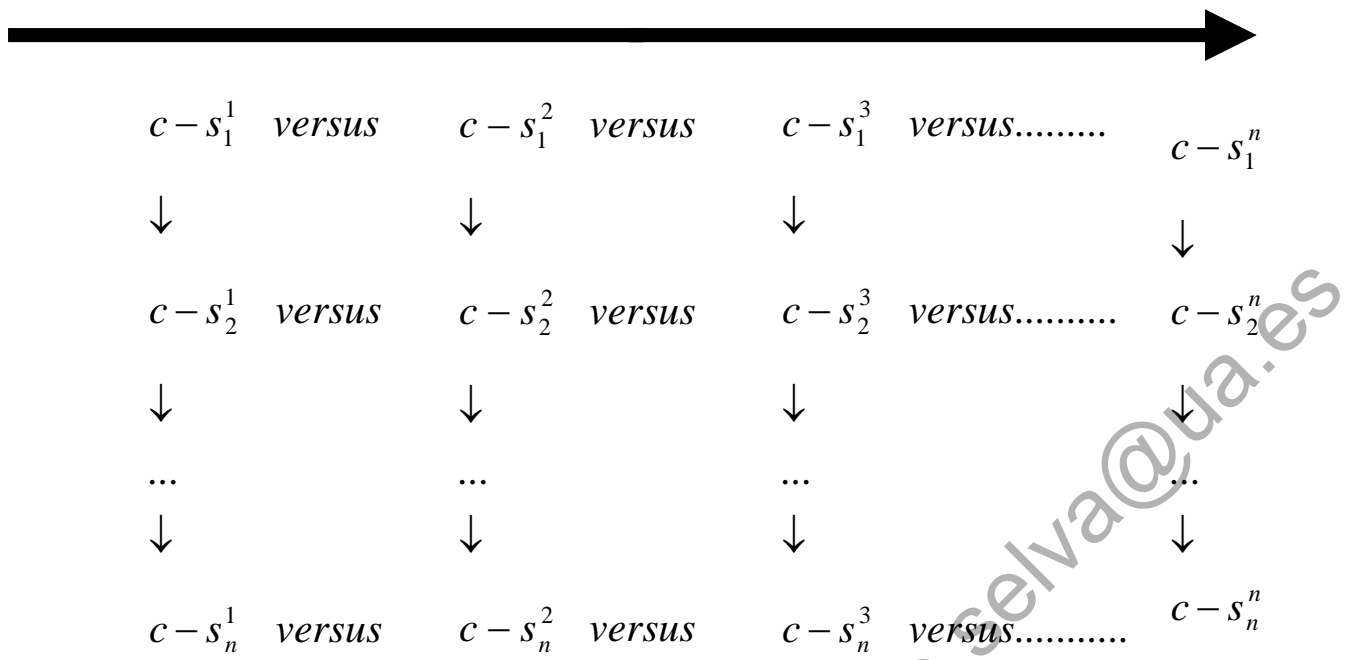

Figure 3: The code.

Rows go on the paradigmatic axis and columns are connotative chains. We are going to establish the following rule of substitution: any connotative significance can be replaced by another one, belonging or not to the same connotative chain.

That which is identical in $\mathrm{n}$ classes of a different object is the cognition or understanding of the concept The definition of a concept that is given in the dictionaries of any language is a summary of the understanding of the concept. This is the subjective component of a concept, and depends on the semiotic system $\Sigma(S)$ that exists in the mind of the subject $S$.

Definition 11: Acconcept is an analytical definition, an abstraction formed in the mind of a subject belonging to a particular semiotic system $\Sigma(S)$.

Definition 12: A formal concept is a concept with formal properties.

Note 3: The concept is a union of denotative and connotative significances (UsóDoménech and Nescolarde-Selva, 2012).

The number of sub-classes contained in $n$ classes assesses the extent or amount as a logical concept. It is the objective component of a concept, and depends on the ontological system. In linguistic theory, it is the designation (d-s). In a lexical designation consisting of the extension of the concept, which in turn constitutes its meaning.

Definition 13: Each denotative significance has a comprehension and an extension. 
Note 4: Comprehensions of the denotative significances are equivalent to the connotative significances.

Example 1: "An animal with an internal skeleton and a segmented column" in 5 classes - fish, amphibians, reptiles, birds and mammals - the comprehension of the concept is vertebrate, and the total number of vertebrate species represents extension.

$$
* * *
$$

We denote denotative significances with italics $d-s_{i}, d-s_{j}$, with normal letters c-s $s_{i}, c-s_{j}$ their comprehensions. Bold denotes $\mathbf{d}-\mathbf{s}_{\mathbf{i}}, \mathbf{d}-\mathbf{s}_{\mathbf{j}}$ extensions of concepts, italics and bold denote $\boldsymbol{d}-\boldsymbol{s}_{\boldsymbol{i}}, \boldsymbol{d}-\boldsymbol{s}_{\boldsymbol{j}}$ propositions. The denotation of set theory is used for extension.

Example 2: The extension of fish being included in the vertebrates, is $\mathbf{d}-\mathbf{s}_{\mathbf{i}} \subset \mathbf{d}$-s $\mathbf{j}$ and thereby the extended relationship is expressed both denotative significances.

Denotation of logic will be used for comprehension.

We have the following operations:

\section{For the concepts (denotative significances)}

Conceptual inclusion: $\subset$

Conceptual conjunction: $\wedge$

Conceptual disjunction: $\vee$

Conceptual implication: $\Rightarrow$

\section{For the extensions}

Inclusion: $\subset$

Intersection: $\cap$

Union: $\cup$

Implicatión: $\Rightarrow$

\section{For the comprehensions}

Semiotic inclusion:

Semiotic conjunction: $\hat{s}$

Semiotic disjunction: $\underset{S}{v}$

Semiotic implication: $\underset{S}{\Rightarrow}$

Theorem 1: Denotative significances form a relationship of increasing order based on their extension and the descending order of their comprehension

Proof:

a) The relation is reflexive because if $d$-s $\subset d$-s, then $\mathbf{d}$-s $\subset \mathbf{d}$-s in extension and c-s $\subset_{s}^{c-s}$ in comprehension. 
b) If $d-s_{i} \subset d-s_{j}$ and $d-s_{j} \subset d-s_{i}$ it is true that $\mathbf{d}-\mathbf{s}_{\mathbf{j}} \subset \mathbf{d}$-si and $\mathbf{d}-\mathbf{s}_{\mathbf{i}} \subset \mathbf{d}$-s $\mathbf{s}_{\mathbf{j}}$ in extension and c-s $\mathrm{s}_{\mathrm{i}} \subset_{s}$ c-s $\mathrm{S}_{\mathrm{j}}$ and $\mathrm{c}-\mathrm{S}_{\mathrm{j}} \subset_{s}{ }^{\mathrm{c}-\mathrm{S}_{\mathrm{i}}}$ in comprehension. This indicates that the property set or property of $d-s_{j}$ is equal to $d-s_{i}$ and conversely, since $d-s_{i}$ and $d-s_{j}$ have the same characteristics, that, $d-s_{i}=d-s_{j}$ and consequently the relation is antisymmetric.

c) If $d$-s $s_{i} \subset d$-s $s_{j}$ and $d$-s $s_{j} \subset d$-s $s_{k}$ then $d$-s $s_{j} \subset d$-si and $d$-s $s_{k} \subset d$-sj, therefore $\mathbf{d}$-sk $\subset \mathbf{d}$-s $s_{\mathbf{i}}$ in extension and $c-s_{i} \subset_{s}$ c-s $s_{k}$ in comprehension. This shows that the properties of $d-s_{j}$ are $d-s_{i}$ and $d-s_{k}$ are those of $d-s_{j}$. The relation is transitive.

Definition 14: Denotative significances are ordered according to chains with increasing order of extension and decreasing order of comprehension.

Note 5: In extension, we go from the part to the whole. However, in comprehension, we will go from whole to part.

We emphasized earlier that comprehension is the subjective component of the concept. For the human mind, the part is more complex then the whole. It is a consequence of the fact that semantic complexity moves from the whole to the particular.

Example 3: The extension of vertebrates, wherein the extension of fish is entirely formed for different fish species, whereas the comprehension of fish (aquatic vertebrates breathing air dissolved in the water, etc.) is more complex than that of vertebrates.

We consider a language as a five-dimensional denotative space, consisting of the following dimensions: extension, comprehension, paradigmatic axis, syntagmatic axis and time axis (Figure 4). 


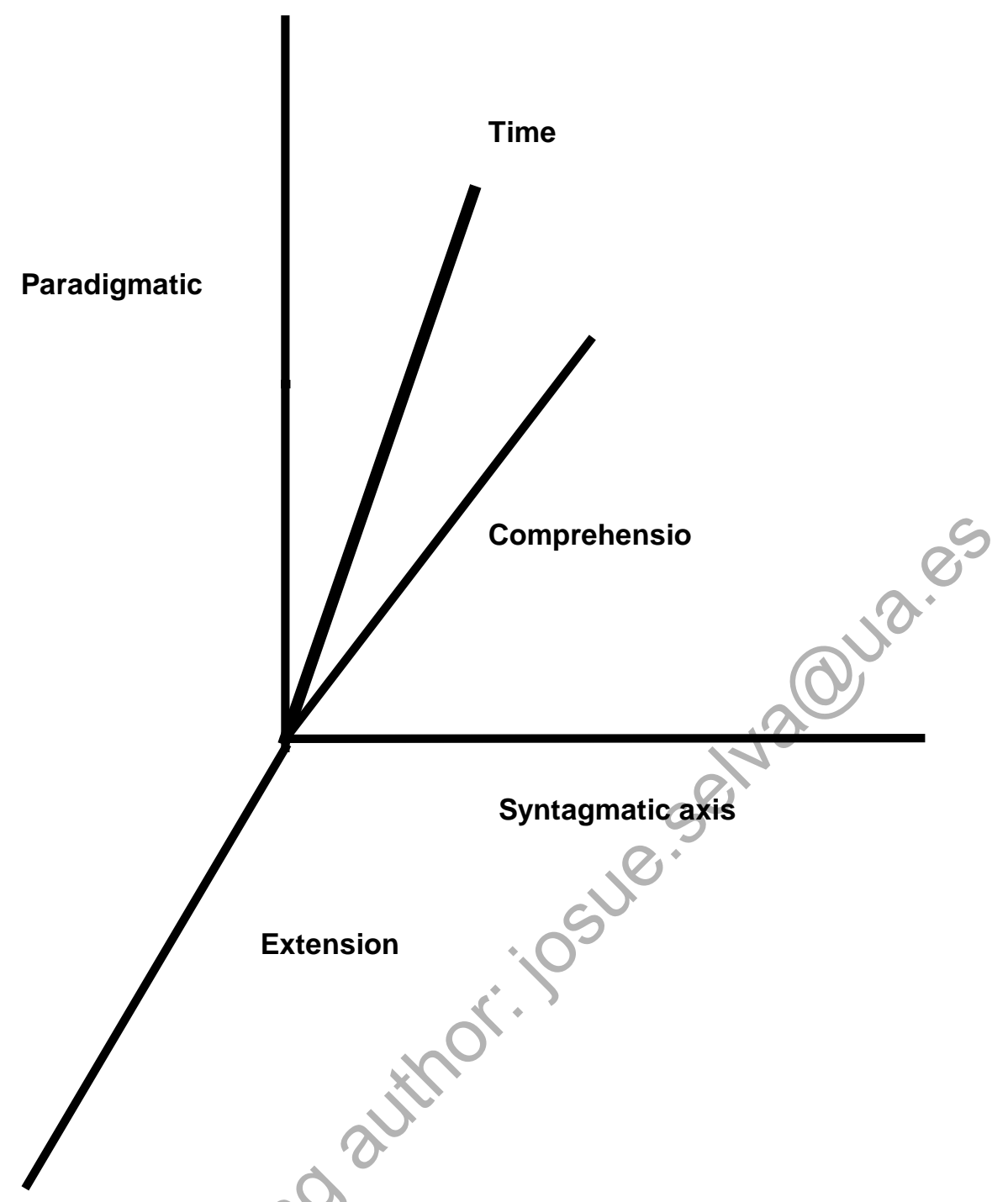

Figure 4: Five-dimensional significance space.

Note 6: Extension and paradigmatic axis expand Reality. Comprehension and syntagmatic axis contract Reality.

Note 7: Extension and paradigmatic axis are dynamicl. Comprehension and syntagmatic axis are static.

Additional study of multidimensional significance spaces will be presented in later writings.

Hypothesis 1: We suppose the existence of an enumerable set of significants which we will call $\square$ such that $\square=\left\{S_{1}, S_{2}, \ldots, S_{\omega}, \ldots\right\}$.

The discoveries in any field of knowledge only find hidden significants and reveal them. These significants were there before discovery but were revealed. 
Hypothesis 2: We suppose the existence of revealed significant subset 3 such that ] $=\left\{S_{1}, S_{2}, \ldots, S_{\omega}\right\}$ and $\mathrm{J} \subset \boldsymbol{}$.

We suppose a series of subsets $\mathbf{J}_{\mathbf{1}}=\left\{S_{1}\right\}, \mathbf{J}_{\mathbf{2}}=\left\{S_{1}, S_{2}\right\}, \ldots . \mathbf{J}_{\boldsymbol{\omega}}=\left\{S_{1}, S_{2}, \ldots, S_{\omega}\right\}$. Let $\boldsymbol{\nabla}$ be a set of denotative significances such that $\boldsymbol{\Xi}=\left\{d-s_{1}, d-s_{2}, \ldots, d-s_{\omega}\right\}$. We establish a bijection between the set $]$ and set 0 such that $f_{D}: J \rightarrow 0$ and $f_{D}\left(S_{i}\right)=d-s_{i}($ fig 5$)$.

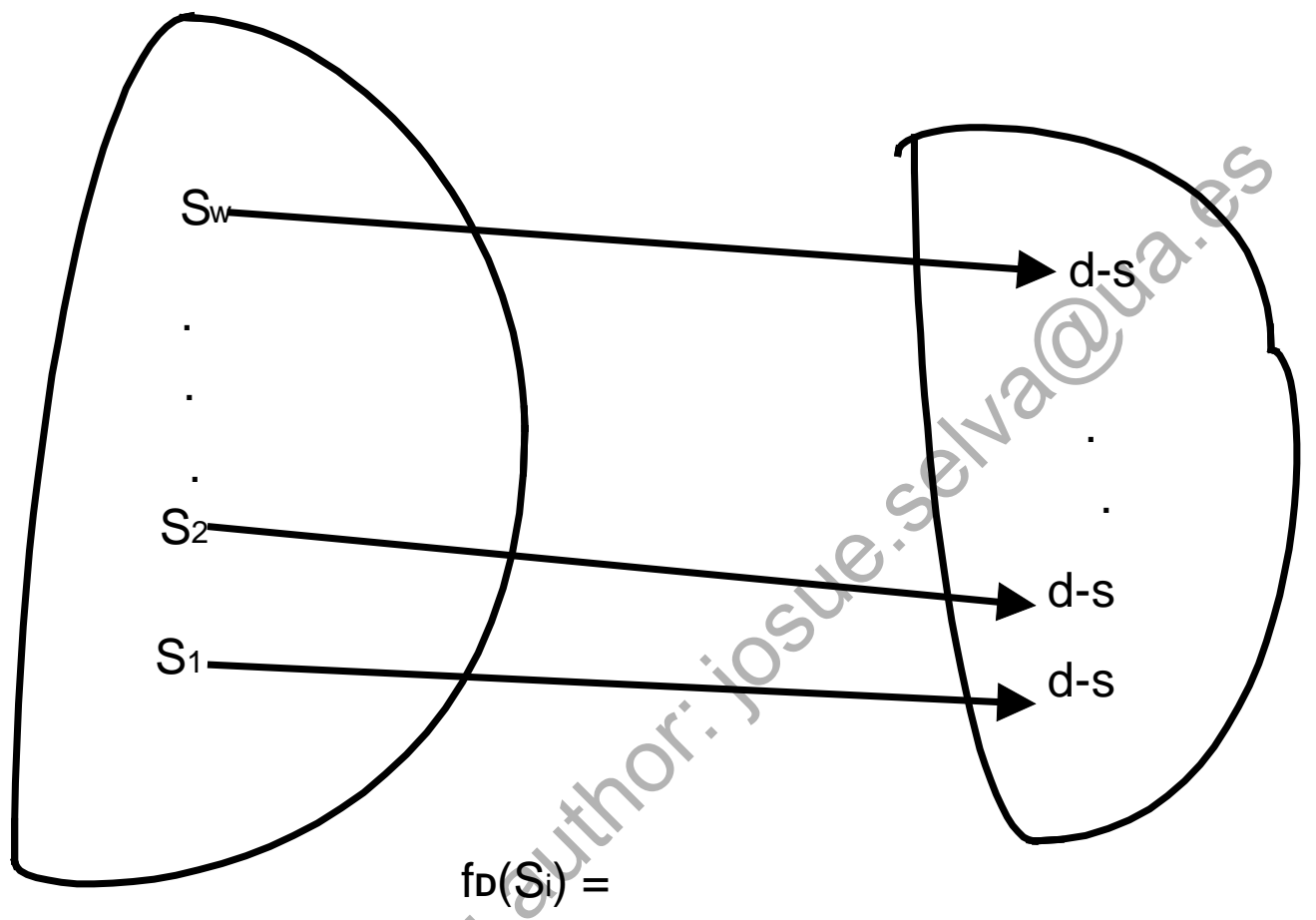

Figure 5: Bijection between $]$ and $\theta$.

Definition 15: To this function $\mathrm{f}_{\mathrm{D}}: \mathrm{J} \rightarrow \boldsymbol{0}$ will call function of denotation.

$\operatorname{Dom}\left(\mathrm{f}_{\mathrm{D}}\right)=\left\{S_{1}, S_{2}, \ldots, S_{\omega}\right\}$

$\operatorname{Rang}\left(\mathrm{f}_{\mathrm{D}}\right)=\left\{d-s_{1}, d-s_{2}, \ldots, d-s_{\omega}\right\}$

Let $\mathrm{L}$ be a set whose elements are lexemes of a specific language and such that $L=\left\{l_{1}, l_{2}, \ldots, l_{\psi}\right\}$.

We will establish a surjective function from the set of denotative significances 8 and the set of lexemes $L$ such that $\mathrm{f}_{\mathrm{L}}(\boldsymbol{\nabla}) \rightarrow \mathrm{L}$ and $\mathrm{f}_{\mathrm{L}}\left(\mathrm{d}-\mathrm{s}_{\mathrm{i}}\right)=\mathrm{l}_{\mathrm{j}}$ (Fig.6). 


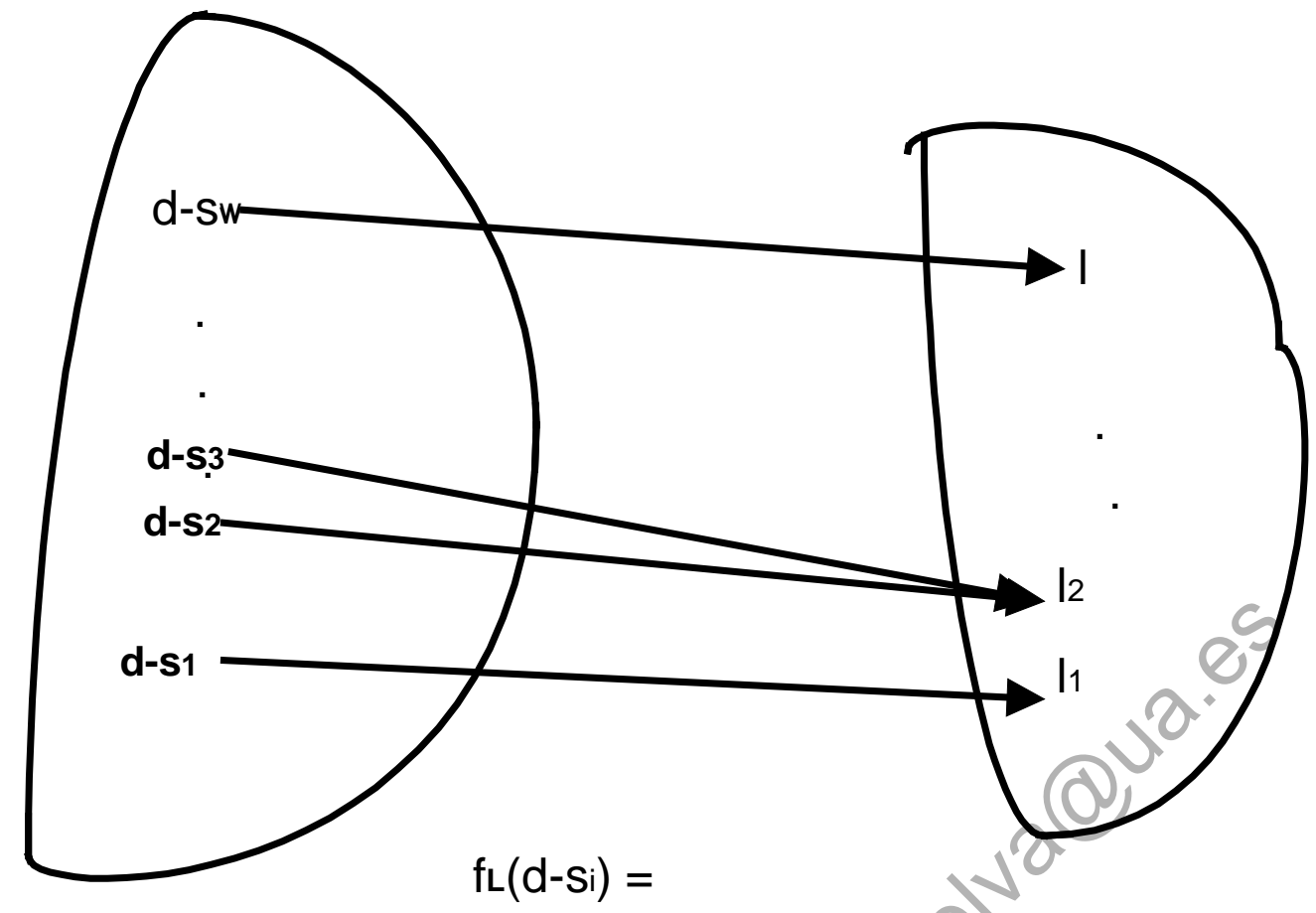

Figure 6: Surjection (onto) between $\sigma$ and $\mathrm{L}$.

Definition 16: To this surjective function (onto) $\mathrm{f}_{\mathrm{L}}(\boldsymbol{\theta}) \rightarrow \mathrm{L}$ will call lexemic function.

The cardinality of the domain of the surjective function $f_{L}(\theta) \rightarrow L$ is greater than or equal to the cardinality of its codomain: $A s f_{L}(\boldsymbol{\theta}) \rightarrow L$ is a surjective function, then has at least as many elements as $\mathrm{L}$, in the sense of cardinal numbers. Then CardL $\leq$ Card

The same lexeme may correspond to different denotative significances.

Example 4: Color is the perceptual property corresponding in humans to the categories called red, blue, yellow, green and others. In particle physics, color charge is a property of quarks and gluons that is related to the particles' strong interactions in the theory of quantum chromodynamics (QCD). Color charge has analogies with the notion of electric charges of particles, but because of the mathematical complications of QCD, there are many technical differences. The color of quarks and gluons is completely unrelated to visual perception of color.

$* * *$

We can make the following composition of functions (Fig. 7): 


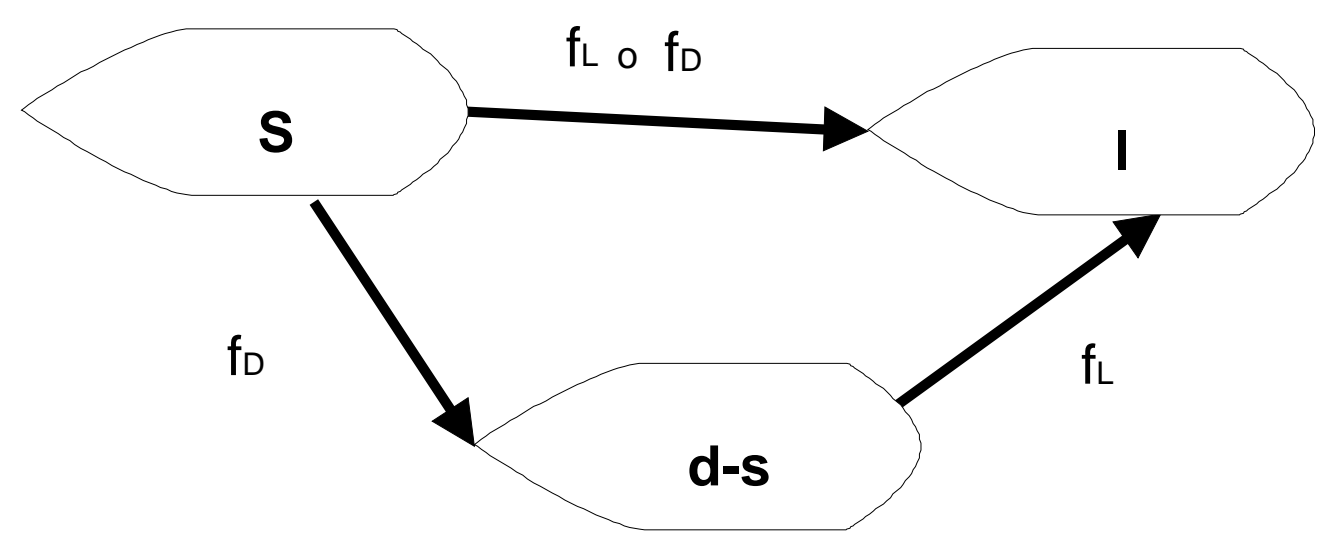

Figure 7: Composition of denotative and lexemic functions.

Let $\mathrm{l}$ be an arbitrary element of $\mathrm{L}$. Since $\mathrm{f}_{\mathrm{L}}$ is surjective, $\exists d-s \in$ such that $\mathrm{f}_{\mathrm{L}}(\mathrm{d}-\mathrm{s})=$ 1. Furthermore, since $f_{D}$ is surjective, $\exists S \in J$ such that $f_{D}(S)=d-s$. Therefore, $f_{L}\left(f_{D}(S)\right.$ ) $=\mathrm{f}_{\mathrm{D}}(\mathrm{d}-\mathrm{s})=\mathrm{l}$, or $\mathrm{f}_{\mathrm{L}}{ }^{\circ} \mathrm{f}_{\mathrm{D}}(\mathrm{S})=\mathrm{l}$.

\section{OVERCOMING -EXPANSION OF LANGUAGE}

We can not completely rely on our language for communication, but at the same time we should not rely blindly onit. How can we trust a limited language? How much connotative significance can the lexemes possess? The existence of different interpretations is proof of failure, in any text, a single meaning, and single connotative significance are intended. Language is a means but it is not an end; the real goal is the maximum capacity of revealing the hidden, yet unknown significants. We must be careful with language, because many times, rather than an essential tool for communication, it can be a veil that hides the deeper sense of reality. If we want to overcome the capacity of language to access a more specific sense, we must rebuild a metalanguage from overcoming the current language. When we refer to the "overcoming of language" we do not speak literally, but metaphorically, what we must do is to destroy the preconceptions of a particular language that prevents us from advancing knowledge of reality ${ }^{4}$.

We must always remember this issue, both by way of overcoming language, as another way of specifying the meaning through the existing language. Therefore, every effort should work in favour of an expansion of a new kind of language that allows us to analyze questions that we cannot understand for lack of linguistic tools. As says de Paz Blanco (2007)

\footnotetext{
${ }^{4}$ It is noteworthy that the discipline of semantics was known much earlier, the Spanish Kabbalist Abraham Abulafia (1240-1292) (become popular in Bee Season, a film starring Richard Gere and Juliette Binoche) that presents ideas that are surprisingly modern. Abulafia tried to skip the limits of language delving into the hidden meanings of writing lexemes. He created metalanguages to overcome literal languages. He specialised in breaking those systems to access meta deeper levels (connotative depth) of each word. He used lexemes as tools to discover the hidden meaning of each of them, in relation to the root or origin of the word.
} 
The word has a border that is most important as hiding what it shows. In the Hindu tradition the word is understood as the other side of silence, speaking the words that express the silence. In Hebrew tradition speaking the word no, means allowing the silence that is hidden by speaking words. So this is the first paradox: what cannot be said unleashes rivers of literature, which is indescribable, it is said. If I explain, I am not silencing.

The process of revealing hidden significants can only be performed if we destroy our current linguistic limitations. Where does overcoming the structural limits of language lead? When we refer to overcoming our linguistic limitations, not only with an expanded language, but we expand the meaning of that literal language to a search of unknown connotative significances. This overcoming of the limits leads inexorably to new limits. But these limits are no longer structural products of language, but that will depend on the capacity of thought. So we have two levels of enlargement

: In paradigmatic extension and connotative depth.

Let $\boldsymbol{\nabla}=\left\{d-s_{1}, d-s_{2}, \ldots, d-s_{\omega}, \ldots\right\}$ be the denotative set. We supose the existence of a sequence de subsets such that $\boldsymbol{0} \boldsymbol{\nabla}=\{\varnothing\}, \quad{ }^{\boldsymbol{V}}=\left\{d-s_{1}\right\},{ }^{2} \boldsymbol{\Theta}=\left\{d-s_{1}, d-s_{2 \omega}\right\}$,

$=\left\{d-s_{1}, d-s_{2}, d-s_{3}\right\}, \ldots ., \quad \boldsymbol{w} \boldsymbol{D}=\left\{d-s_{1}, d-s_{2}, \ldots, d-s_{\omega}\right\} \subseteq$ Let $\quad\left\{t_{0}, t_{1}, t_{2}, \ldots, t_{\omega}\right\}$ be a temporal sequence.

Definition 17: We define paradigmatic extension the sequence ${ }^{0} \boldsymbol{\nabla}\left(t_{9}\right),{ }^{1} \mathbf{D}\left(t_{1}\right),{ }^{2} \mathbf{O}\left(t_{2}\right)$, ${ }^{3} \boldsymbol{\nabla}\left(t_{3}\right), \ldots{ }^{w} \boldsymbol{\nabla}\left(t_{w}\right)$. (Fig 8.) 


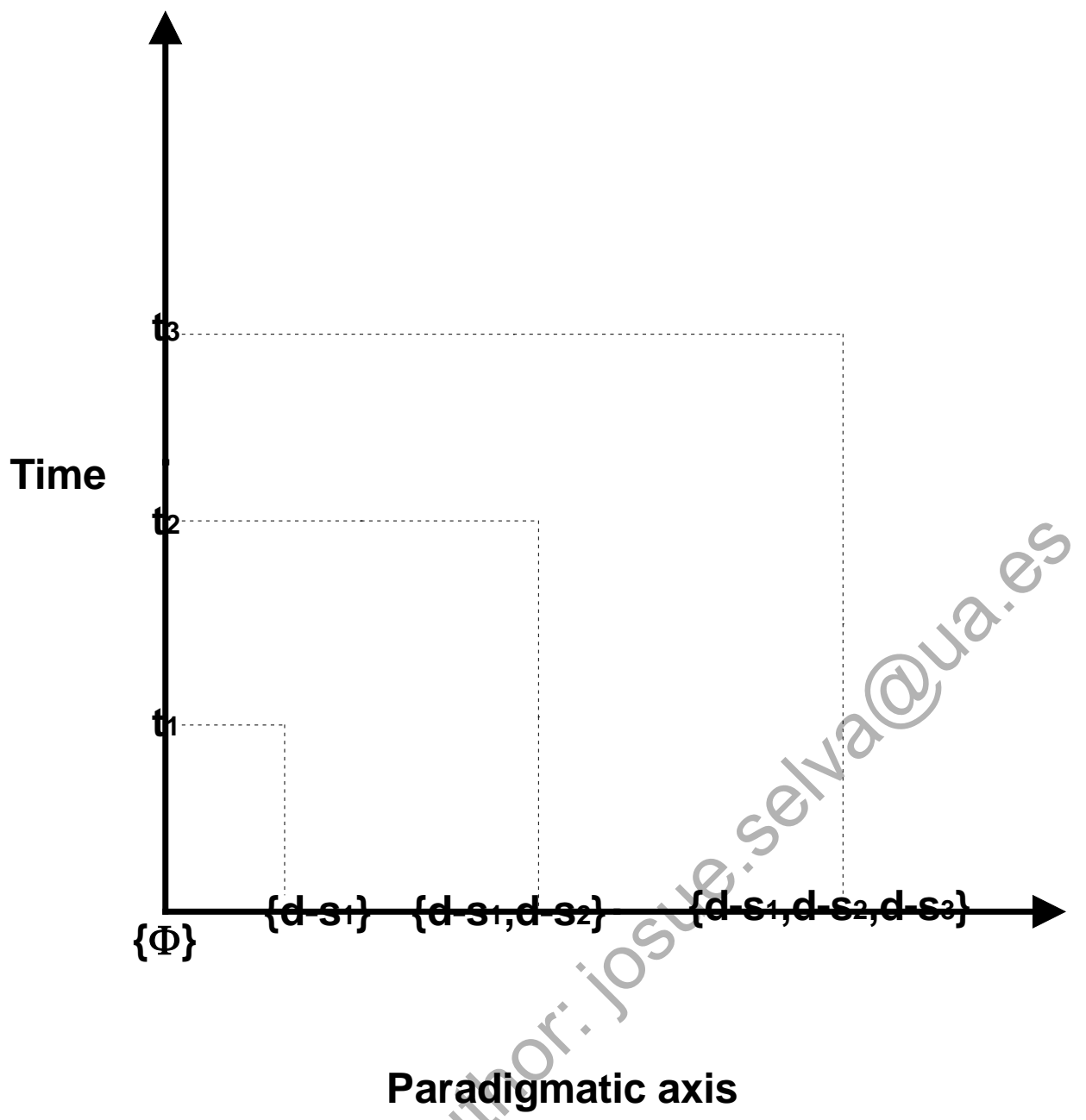

Figure 8: The paradigmatic extension.

Definition 18: We define as connotative deepening to the process of acquiring a broader comprehension of a particular denotative significance, with the property that this new comprenhesion can replace the previous connotative significances.

\section{Example 5:}

Significant: QY

Denotative-significance: The Sun.

Connotative-significances:

$c-s_{1}=$ The Sun is a god.

$c-s_{2}=$ Anaxagoras reasoned that it was a giant flaming ball of metal even larger than the Peloponnesus rather than the chariot of Helios, and that the Moon reflected the light of the Sun.

$c-S_{3}=$ The Sun is a star but Earth is the center of the universe and the Sun revolves around the earth. Ptolemy estimated the distance as 1,210 times the Earth radius, approximately 7.71 million kilometers.

$c-s_{4}=$ Arabic astronomical contributions included discovery that the direction of the Sun's apogee is changing. 
$c-S_{5}=$ Copernicus's heliocentric theory. The Sun is the center and the Earth goes around the sun.

$c-s_{6}=$ The Sun is not the center of the universe. It's just one more star in a cluster known as a Galaxy.

$c-\mathrm{S}_{7}=$ The Sun is the star at the center of the Solar System. It is almost perfectly spherical and consists of hot plasma interwoven with magnetic fields. It has a diameter of about 1,392,684 km, about 109 times that of Earth, and its mass (about $2 \times 10^{30}$ kilograms, 330,000 times that of Earth) accounts for about $99.86 \%$ of the total mass of the Solar System. Chemically, about three quarters of the Sun's mass consists of hydrogen, while the rest is mostly helium. The remainder $(1.69 \%$, which nonetheless equals 5,628 times the mass of Earth) consists of heavier elements, including oxygen, carbon, neon and iron, among others.

$\cdot$
$\cdot C-S_{n}$

We can summarize this process of deepening in Figure 9. 


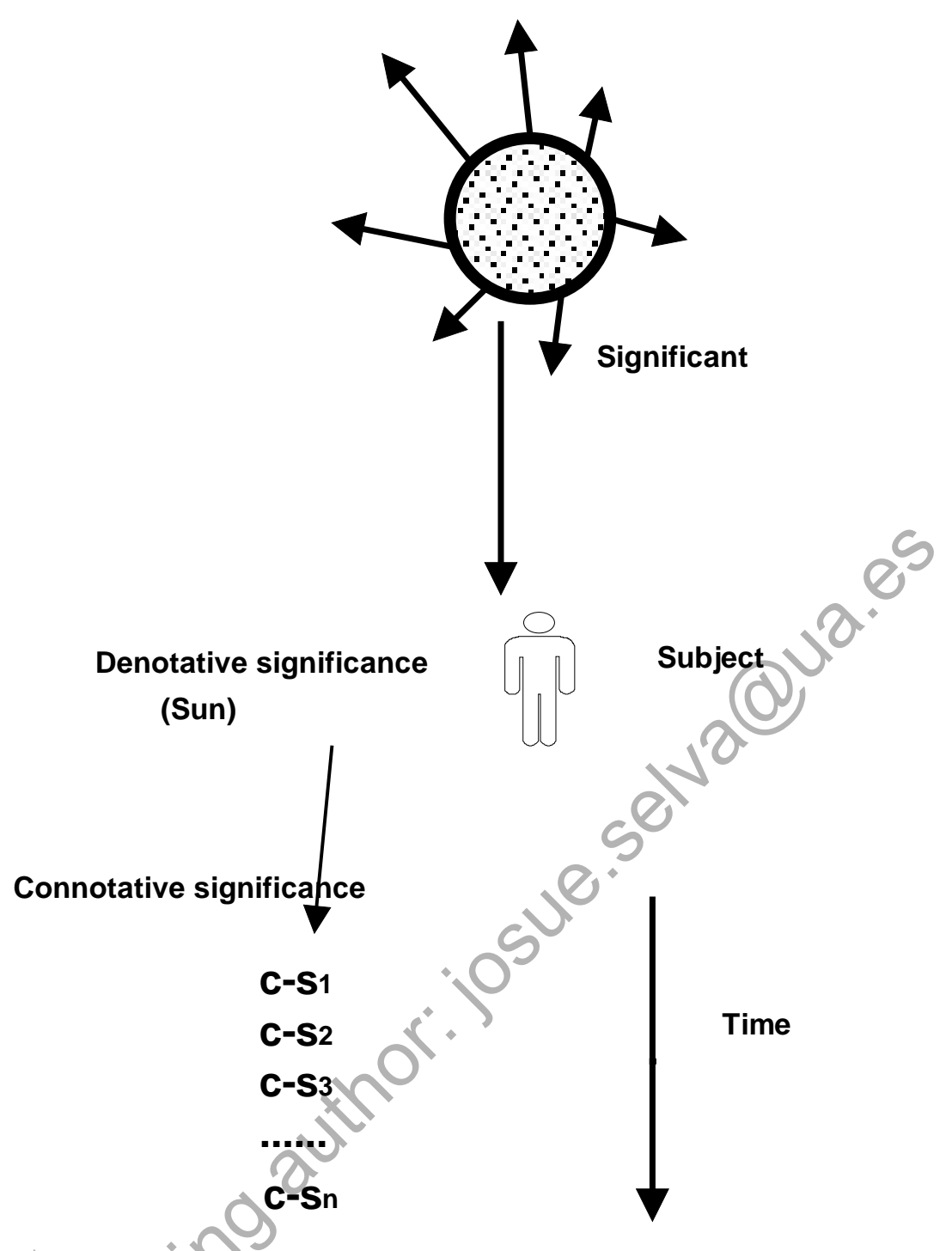

Figure 9: Process of connotative deepening ${ }^{5}$.

A limited capacity is reflected in our language; therefore, to reflect the expansion of thought, the language must be expanded. And through a cybernetic process that expands the language, there is an expansion of thought. We cannot expand thought if it not expressed within the language. And we cannot expand the language if there is not a need to reflect a certain type of thinking. Now, when we can make this a kind of original thinking within a language, this is when it expands. And when the language reflects the limits of thought, this is when you can again expand thinking beyond the limits

${ }^{5}$ The above example corresponds to the ideal case of a single culture. Understanding a culture other than ones own essentially involves understanding intersubjective rules that give meaning to actions and cultural products. In the language of an African people the lexeme ango means dog, but this tells us nothing about what a dog means for natives (do they hunt with their dogs or eat them, etc..), in contrast to what it means for a Westerner. If this happens with a simple term like a dog, how much greater is the disturbance when to bump into terms having a metaphysical reference? (Evans-Pitchard, 1965). 
expressed within the language. It creates a vicious circle where with further expansion within the language there is greater unification and understanding of reality. The thought always expands beyond all possible language. The fact is that to communicate "hidden" thought we should "reveal" through language. And it is then that the process of linguistic revelation is the result of a revelation of thought that precedes it, but cannot expand more as the language has not been expanded in advance. This lack of expansion of language in turn prevents further expansion of thought, because the thought, to continue advancing, needs a few axioms or support points, which are precisely the constituents of language. Therefore, the expansion of language ${ }^{6}$ does not produce a mere description of the thoughts, but creates the basic lexemes for the future development of thought. We need then the existence of a special word to develop a certain type of thought, which could not be developed if we do not have the first word that is the fulcrum for new forms of knowledge. It is a temporary foothold, because we can always find specific words that can better clarify the discovered reality. Language is, in this sense, what creates new connections for the advancement of knowledge. The more connections are established, the more we can described the greater complexities of the hidden reality, which is hidden by default by just such connections.

\section{IS THERE AN IMPOSSIBILITY KNOWING REALITY?}

Let's make two different conceptions about knowledge of reality

\subsection{Spinozian conception}

For Spinoza (2007) a thing $\Phi$ either exists $\exists \Phi$ or or doesn't $\neg \exists \Phi$ (first premise); where reality is co-extensive with a deductive, axiomatic system, it then follows that:

1) $\exists \Phi$ as existing - it necessarily exists (because existence is co-extensive with a deductive, axiomatic system: its existence follows logically from those axioms)

2) $\neg \exists \Phi$ as non-existing - it necessarily does not exist (its existence must involve a logical contradiction within the axiomatic system)

3) And so: if we cannot show that a thing cannot exist (i.e., if we cannot show that a thing's existence involves a logical contradiction, as with the square circle), then the only other possibility is that it must exist (its existence must follow logically from the axioms of the system.)

\subsection{Neoplatonic and mystical conception}

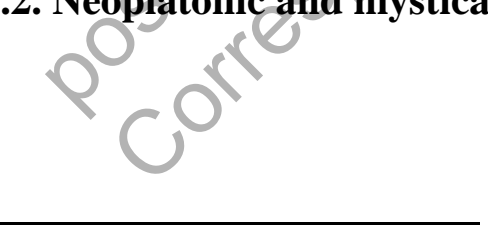

\footnotetext{
${ }^{6}$ What has unfortunately happened is a restricted expansion of language within each discipline in modernity. This expansion occurs within each scientific discipline independently, so that we now have another serious problem: we discovered that coordination between the languages of the various disciplines does not exist (despite language expansions), which leads to more confusion. Language has been expanded with separate form and now we do not know equivalences, which means the expansion of actual language has turned against ideas which should work towards the expansion of language. If the expansion of language should aim at a better understanding of the hidden realities, now that expansion has only served to disconnect the various fragments of reality and, to the lose linguistic equivalence on the depth of each cognitive discipline, we are in a new Tower of Babel. The worst language confusion are now different existing languages, and specialized languages that exist within each of the disciplines.
} 


\begin{abstract}
${ }^{7}$ Plato's metaphysics is divided into four levels of reality and four epistemological ways of apprehending the Forms. The four levels of reality are: images, sensible objects, lower forms, higher forms. The four epistemological ways of apprehending are imagination, perception, reasoning and understanding. Those on one level of reality or awareness cannot recognize what is being said by those on a higher level. The lowest level of awareness is illusion. Illusion is the practice of holding opinions based solely on appearances, unanalyzed impressions, uncritically inherited beliefs, and unevaluated emotions. The next level is informed awareness, which attempts to distinguish appearance from reality in an "everyday", common-sense way. Informed awareness is based on observations and perceptions of physical objects, not just images or representations of them. These lower two levels of awareness are part of the "becoming" layer of awareness and use the "becoming" layer of physical reality. The next level of awareness moves out of the realm of becoming and into the realm of being. This is the first stage of knowledge acquired through deductive reasoning. The final and highest level of reality moves beyond deductive reasoning. At this level, the soul has no need for perception or interpretation. Higher forms are directly understood, apprehended, and glimpsed. A further concept in Plato's metaphysics is that of The Good (Plato's God). The Good is the highest form possible. It makes the existence of everything else possible. The Good cannot be observed with the five senses and can be known only by pure thought and intelligence. In Plato's Timaeus, the Demiurge is really an intermediary between the essential realm of non-materiality and the world of matter. The Demiurge takes the inert substance of matter and acts upon it, bringing forth the templates of life from the realm of thought into the realm of matter.
\end{abstract}

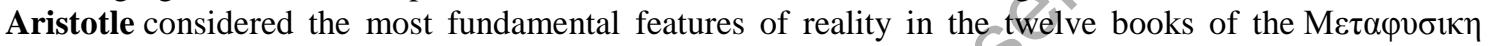
(Metaphysics). Although experience of what happens is a key to all demonstrative knowledge, Aristotle supposed that the abstract study of "being qua being" must delve more deeply, in order to understand why things happen the way they do. A quick review of past attempts at achieving this goal reveals that earlier philosophers had created more difficult questions than they had answered: the Milesians over-emphasized material causes; Anaxagoras over-emphasized mind; and Plato got bogged down in the theory of forms. Aristotle intended to do better. Although any disciplined study is promising because there is an ultimate truth to be discovered, the abstractness of metaphysical reasoning requires that we think about the processes we are employing even as we use them in search of that truth. As always, Aristotle assumed that the structure of language and logic naturally mirrors the way things really are. Thus, the major points of each book are made by carefully analyzing our linguistic practices as a guide to the ultimate nature of what is. Philo of Alexandría equates this with the Logos, whom he refers to as the "man of God". The Logos was originally conceived of as the active role of God as the principle of reason. To this Philo adds Plato's idea of forms, transforming the Logos into the Divine Mind - the idea of ideas or form of forms. The Logos becomes the eternal Form of Wisdom for Philo. According to Plotinus, the basis of all reality is an immaterial and indescribable reality called the One or the Good. There are several levels of reality that emanate from the One or the Good, much like ripples in a pond emanate from a dropped stone. The second level of reality is Mind or Intellect (nous). Mind results from the One's reflection upon itself. The levet below Mind is Soul. Soul operates in time and space and is actually the creator of time and space. Soul looks in two directions - upward to Mind and downward to Nature which created the physical world. The lowest level of reality is matter. According to Plotinus and Neo-Platonism, matter is viewed very negatively. Plotinus, himself, held such disgust for physical things that he despised his own body. He did not celebrate his own birthday since the birth of his physical body was nothing to be celebrated. He also did not take care of his physical health or hygiene. For example, Plotinus had puss-filled sores on his body that he refused to care for. Unfortunately for his students, he liked to embrace his pupils, causing many of them to flee from their teacher. The function of language, or the extent to which language can function, is as the mirror reflection of the intellectual in discursive reason, in the facilitation of memory, in that, as Plotinus says, the verbal expression unfolds its content and brings it out of the intellectual act into the image-making power, and so shows the intellectual act as if in a mirror, and this is how there is apprehension and persistence and memory of it. The mechanism of perception mediates between the sensible world of objects in nature and the inaccessible intellectual, or nous, in a dialectical process between the subject and the world. There must be an affection which lies between the sensible and the intelligible, as Plotinus puts it, a proportional mean somehow linking the two extremes to each other, the sensible form and the intelligible form. In the perception of an object, the object is already apprehended by the perceiving subject in relation to the perceiving mechanism, the construction of intellect involving the mnemic residue and the intelligible form, through the use of geometry, as vision is understood in 
thought. Let $\boldsymbol{\aleph}^{8}$ be the Absolute Reality ${ }^{9}$. Any proposal on Reality must be included in one of the four following categories:

$$
\begin{aligned}
& \text { P1) } \\
& \text { P2) } \neg \\
& \text { P3) } \boldsymbol{\aleph} \wedge \neg \\
& \text { P4) neither } \boldsymbol{\aleph} \text { nor } \neg \boldsymbol{\aleph}
\end{aligned}
$$

\section{Theorem 2: Any proposition based on a certain language $\mathbf{L}$ that includes the Reality $\mathbf{\aleph}$ contradicts itself.}

Proof:

relation to geometry and mathematics, the intelligible mechanisms as the underlying structure. In the Long Commentary on the De anima 3.1.5, Averroes posits three intelligences in the anima rationalis or the rational soul: agent intellect, material or passible intellect, and speculative or actualized intellect, also called acquired intellect. While material intellect is "partly generable and corruptible, partly eternal," corporeal and incorporeal, the speculative and agent intellects are purely eternal and incorporeal. Actualized intellect is the final entelechy, or final actualization of potentiality. It is a form of intellectus in habitu, which can be both passive and active, corporeal and incorporeal. Material intellect is a possible intellect, a possibility, because it is both corporeal and incorporeal, thus neither corporeal nor incorporeal. Material intellect becomes actualized intellect through the affect of the agent intellect, which illuminates, as a First Cause, the intelligible form or forma imaginativa, the residue of the sensible form, the sensation, in the anima rationalis. The illuminated intelligible acts on material intellect until material intellect becomes actualized intellect, at which point intellect is able to act on the intelligible. Maimonides' negative theology is complemented by other elements of his epistemology. He held that there are significant limitations on what human beings can demonstrate scientifically. It is essential to Maimonides' philosophical anthropology that human beings have an intellectual essence, a rational nature capable of comprehending intelligible features of reality. Again, to say that man is created in God's image is to say that a human being has a rational soul. In Maimonides' view Adam and Eve could have led untroubled lives guided exclusively by clear intellectual conceptions of the true and the false, without concern with good and evil. Such lives would have been free of frustration, pain, anxiety, and fear. All that was required was that Adam and Eve heed the injunction not to eat of the tree of the knowledge of good and evil. In eating of the tree they yielded to distraction from intellectual activity and sought satisfaction in the lesser objects of the imagination. Good and evil are not, in Maimonides' view, demonstrable or intuited intelligibles. Our conceptions of good and evil involve the imagination.

${ }^{8}$ We have chosen the Hebrew letter Aleph used in the sense of Jewish mysticism: "God is One": the absolute unity of God. "There is none other besides Him:" "One, single, and unique. "One counts "nothing from something

\footnotetext{
${ }^{9}$ For Jewish mysticism, the only reality is Ein Sof as there is no time and space (Scholem, 1964). For there to be variables of time and space, reality must be created of emptiness. This is temporary according to whether Ein Sof is admitted into the vacuum, occupies it and nullifies the variables of time and space. Our reality is named with the letter $ב$ and is a spatiotemporal reality derived from the true reality of level and is called the reality of Ein Sof.
} 
1) By P1 it is affirmed that $\boldsymbol{\aleph}$ must be a being with the categories of absolute, infinite and limitless. Nevertheless, an absolute and limitless being $\boldsymbol{\aleph}$ excludes $\neg$ $\boldsymbol{\aleph}$, and all exclusion is limitation. Therefore, the limitless being is limited and the affirmation is contradicted by itself.

2) By P2, $\neg \boldsymbol{N}$ excludes the being $\boldsymbol{N}$ and therefore it is limited, and the affirmation is contradicted by itself.

3) By P3, reality includes as much $\mathbf{\aleph}$ as $\neg \mathbf{\aleph}$, that it is inherent as much in the one as in the other, but this excludes it from not being either the one or the other, to transcend $\boldsymbol{\aleph}$ and $\neg \boldsymbol{\aleph}$. The affirmation is contradicted by itself.

4) By P4, if is affirmed that neither $\mathbf{\aleph}$ nor $\neg \mathbf{\aleph}$, and it transcends both, excluding it from the property of immanency, that is to say to be equipped with $\wedge \neg$ Therefore, the affirmation is contradictedby itself.

Therefore, since all affirmation belonging to a certain language $\mathrm{L}$ only has sense based on its opposite, it has been demonstrated that any affirmation is relative and if the same conceptthe Reality $\mathbf{N}$, will be contradictory.

A direct and positive affirmation on reality must be necessarily contradictory or devoid of meaning.

a) It is contradictory as soon as the own affirmation comprises the Reality $\mathbf{\aleph}$, therefore talking about itself, and all affirmation trying to affirm something on itself usually is contradictory.

b) It is devoid of meaning because to describe the whole is equivalent to not describe anything.

This process corresponds to the futile attempt to divide the universe into observer and observed, narrative and narrated, separating it and joining it is thus false with the sameSubject. The linguistic communication, that in the amplest sense is simply the transmission of a concatenation of words, is not more than the reflection of the reality in a mirror of illusion. Two types of symbolic elaborations used by language exist to indicate or to suggest reality and that can be used in three main ways to speak about reality. Both types of symbolic elaborations are the following:

1) Linear, one-dimensional, analytical and logical elaboration, and where a collection of symbols meticulously defined connects, one after another one, in a line, in agreement with its own particular syntax. It is the corresponding elaboration for scientific, philosophical and symbolic legal text.

2) The imaginative symbolic elaboration. It is pictorial and multidimensional, being in myths, artistic elaboration, poetry, dreams and imagination. It lacks logic, in the strict sense of the word, but it locks up a meaning in a totally different way from the linear elaboration.

Further developed study of paraconsistent logic applied to religious and mystical thought and mathematics applied to symbolism will written about laterpublications. 


\section{CONCLUSIONS}

According to Watts (2006), to study Eastern philosophies, especially Zen, it is remarked that the world of events and entities are more measured terms than phenomenological realities. To fulfill its function (linguistics), the names and terms should be syntactically fixed like all the other units of measurement and comparison. But their use is so successful that the danger of confusing these terms of measurement and comparison (model) with the measured world, is to confuse convention with ontology, and to reduce the rich reality to the model. Linguistic structure with which we form judgments or propositions does not allow a transitive verb without a subject or predicate. As Watts (2006) says, when there is "knowledge", the grammatical convention requires the existence of the knower and that which is known. Man is so used to it that when we talk and think, to build our models, he does not realize that it is just that, a convention, and that does not correspond to the actual experience of knowledge.

The greatness and tragedy of man, his greatest adventure, knowledge, oscillates between two mythological characters Prometheus and Sisyphus. The first, stoleffire from the gods. The second was condemned eternally to roll a rock up a mountain and reach the summit, but the rock rolls back to the foot of the mountain each time, so, eon after eon, so the work is useless. The stone of Sisyphus, with its eternal and useless rolling back from the top is one image of knowledge. The fire of knowledge itself drags the ashes of ignorance. Linguistic structures themselves impede the fullapprehension of Reality $\mathbf{\aleph}$. Just being aware of it, just knowing our limits, we canbegin to catch a glimpse of the Reality $\boldsymbol{\aleph}$ that is being continually denied. And the only way we will achieve a basic principle of knowledge, which is so forgotten: humility.

\section{REFERENCES}

Agazzi, E. 1992. Some Philosophiçal Implications of Gödel's Theorem. In: Kurt Gödel. Actes du Colloque, Neuchâtel 13-14 juin 1991. (Denis Miéville, editor). Travaux de Logique. 7. 129-159.

Benacerraf, P. 1965. What numbers could not be. Philosophical Review.74, 47-73.

Bernays, P. 1935. On Platonism in Mathematics. Reprinted in Benacerraf and Putnam (1983).

Bigelow, J.1988. The Reality of Numbers: A Physicalist's Philosophy of Mathematics. Clarendon. Oxford.

Carnap, R. 1942. Introduction to Semantics. Cambridge. Mass.

Carnap, Rudolf. 1964. Meaning and Necessity, 4th ed. Chicago.

Carnap, Rudolf. 1967.The Logical Structure of the World/Pseudoproblems in Philosophy, trans. by Rolf A. George. Los Angeles.

Chomsky, N. 1963. Some basic concepts of Linguistic. In: Handbook of Mathematical Psychology. Vol II. (Edit. Luce, Bush and Galanter). John Wiley \& Sons. New York, London. 
Chomsky, N. 1965. Aspects of the Theory of Syntax. MIT Press. Cambridge, Massachuconjuntots.

Chomsky, N. 1969. Syntactic Structures. Mouton, La Haye.

Descartes, R. 1960. Meditations on First Philosophy, 2nd ed., trans. by Laurence J.

Lafleur. New York.

Evans-Pritchard, E, E. 1965. Theories of Primitive Religion. Oxford University Press.

Fonsegrive. M.1909. Essais sur la connaissance. París. (In French).

Giddens, Anthony.1976. New Rules of Sociological Method: a Positive Critique of interpretative Sociologies. Hutchinson. London.

Gellner, E. 1998. Language and solitude. Wittgenstein, Malinoski and the Hasburg dilemma. Cambridge, University Press.

Gödel, K. 1931. Über formal unentscheidbare Sätze der Principia Mathematica und verwandter Sistemae I. Monatshefte für Mathematik und Physik, 38. 173-198.

Gödel, K. 1964ㄹ. Russell's Mathematical Logic. Philosophy of Mathematics, ed. by P. Benacerraf and H. Putnam. Englewood Cliffs, 1964,-pp. 211-232.

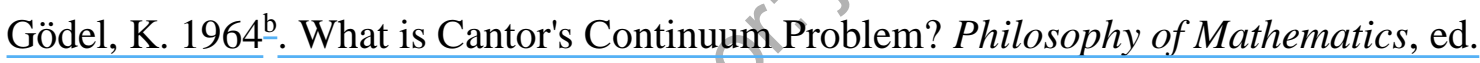
by P. Benacerraf and H. Putnam. Englewood Cliffs, , pp. 258-273.

Hegel, G.W.F. 1948. Wissenschaft der Logik. Verlag von Felix Meiner. Leipzig. (In German).

Hjelmslev, L. Structure fondamentale du langage. Ed. De Minuit. Paris. 1968. (In French).

Hume, D.1964. A Treatise of Human Nature, ed. by L. A. Selby-Bigge, Oxford,

Kant, 1. 1978. Crítica de la razón pura. Madrid: Alfaguara. (In Spanish)

Maddy, P. 1990. Realism in Mathematics. Clarendon. Oxford.

Meinong, A. 1904. Über Gegenstandtheorie. Leipzig: J. A. Barth. (In German).

Nescolarde-Selva, J. 2010. A Systemic Vision of Belief Systems and Ideologies. Doctoral Thesis. Universidad de Alicante. Alicante. Spain. (In Spanish).

Nescolarde-Selva, J., Vives Maciá, F., Usó-Doménech, J.L., Berend , D. 2012a . An introduction to Alysidal Algebra I. Kybernetes 41(1/2), pp. 21-34. 
Nescolarde-Selva, J., Vives Maciá, F., Usó-Doménech, J.L., Berend , D. 2012르. An introduction to Alysidal Algebra II. Kybernetes 41(5/6), pp. 780-793.

Nescolarde-Selva, J. and Usó-Doménech, J.L. 2012 . An introduction to Alysidal Algebra III. Kybernetes. 41(10), pp. 1638-1649.

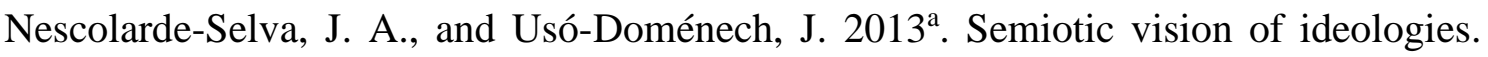
Foundations of Science. DOI:10.1007/s10699-013-9329-8.

Nescolarde-Selva, J. A., and Usó-Doménech, J. 2013 ${ }^{\mathrm{b}}$. Reality, Systems and Impure Systems. Foundations of Science. DOI: 10.1007/s10699-013-9337-8.

Nescolarde-Selva, J. and Usó-Doménech, J.L. 2013드. An introduction to Alysidal Algebra V: phenomenological components. Kybernetes. 42(8), pp. 1248-1264.

De Paz Blanco, M.del R. 2007. Lenguaje y experiencia en la mística judía. Doctoral Thesis. Universidad Complutense de Madrid. Madrid. Spain. (In Spanish)

Renouvier. 1891. Les dilemmes de la metaph. pure .París. (In Freneh).

Shapiro, S. 1997. Philosophy of Mathematics: Structure and Ontology. Oxford University Press. Oxford.

Scholem, G. On the Kabbalah and its Symbolism. Sehocken Books. New York. 1969.

Spinoza, B. 2007. The Ethics. Transladated from the Latin by R.H.M. Elwes. Wilder Publications-

Stoneham, Tom. 2002. Berkeley's World: An Examination of the Three Dialogues. Oxford: Oxford University Press.

Ulin, R. C. 1990. Antropología y Teoría social. Siglo XX. México. (In Spanish).

Usó-Domènech, J.L.and Nescolarde-Selva, J. 2012. Mathematical and Semiotic Theory of Ideological Systems. Lambert Academic Publishing. Saarbrucken. Germany.

Usó-Doménech, J. L. and Nescolarde-Selva, J. 2013. An introduction to Alysidal Algebra IV. Kybernetes 42(8), pp. 1235-1247.

Watts, A. 2006. El camino del Zen. RBA. Coleccionables. SA. (In Spanish)

Winch, P. 1964. Understanding a Primitive Society. American Philosophical Quarterly I, pp. 307-24.

Winch, P. 1990. Ciencia social y filosofía. Amorrortu Eds. Buenos Aires. (In Spanish).

Wittgenstein, L. 1953. Philosophische Untersuchungen. Blackwell. Oxford. 


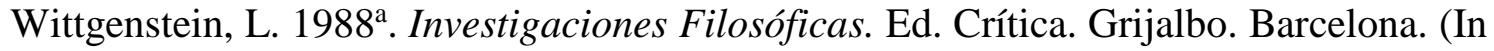
Spanish).

Wittgenstein, L. 1988b . Sobre la certeza. Gedisa. Barcelona. (In Spanish).

Wittgenstein, L. 2001. Tractatus logico-philosophicus, trad. Gilles-Gaston Granger. Gallimard, Paris. (In French) 